\title{
Equity Market Misvaluation, Financing, and Investment
}

\author{
Missaka Warusawitharana* and Toni M. Whited ${ }^{\dagger}$
}

First version, July 10, 2011

Revised, September 18, 2012

\footnotetext{
* Board of Governors of the Federal Reserve System. $20^{\text {th }}$ and C Streets, NW, Washington, DC 20551. Missaka.N.Warusawitharana@frb.gov. (202)452-3461.

${ }^{\dagger}$ William E. Simon Graduate School of Business Administration, University of Rochester, Rochester, NY 14627. (585)275-3916. toni.whited@simon.rochester.edu.

We thank Yunjeen Kim for excellent research assistance. We have also received helpful comments and suggestions from Jianjun Miao, Gregor Matvos, and seminar participants at the SEC, the Federal Reserve Board, Georgetown, INSEAD, HEC-Paris, Colorado, Tulane, the European Winter Finance Summit, Toulouse, Bologna, UCSD, UTDallas, University of Georgia, Georgia State, the 2011 SITE conference, the WFA, and the NBER. All of the analysis, views, and conclusions expressed in this paper are those of the authors and do not necessarily reflect the views or policies of the Federal Reserve Board.
} 


\title{
Equity Market Misvaluation, Financing, and Investment
}

\begin{abstract}
We quantify the extent to which nonfundamental movements in a firm's stock price affect its policies. We estimate a constant returns neoclassical investment model in which firms can finance with equity or cash net of debt. Equity values can be subject to misvaluation shocks. In the model, firms naturally issue equity when it is overvalued and repurchase equity when it is undervalued. Depending on the model parameters, the funds flowing to and from these activities can come from changes in either investment or net cash. We find that the model fits a broad set of data moments in large heterogeneous samples and across industries. It also reproduces features of the data not used in its estimation. Counterfactual exercises show that firms respond to misvaluation shocks more by adjusting financial policies than by adjusting investment. Managers' rational responses to possible misvaluation increase intrinsic shareholder value by up to $8 \%$.
\end{abstract}




\section{Introduction}

We estimate a dynamic model of a firm's investment and financing policies to understand and quantify the distortions to these policies that arise because of equity mispricing. This inquiry is of interest in light of stock market volatility that often dwarfs the volatility of real activity (Shiller 1981). For example, the sharp stock market crash of 2008 was followed by a complete rebound over the subsequent two years, and the technology boom in the late 1990s was followed by a marked reversal in the early 2000s. During these periods, although real activity fluctuated in the same direction, the magnitudes were much smaller. The mere existence of such wide fluctuations in equity values relative to real activity raises the question of whether these swings reflect movements in intrinsic firm values. If not, then it is natural to wonder whether such movements in equity values affect managerial decisions. Put simply, does market timing occur, and how large are its effects?

As surveyed in Baker and Wurgler (2012), many studies have tackled this question. However, the literature lacks investigations of the quantitative importance of market timing. This type of

study is interesting in that economists naturally wish to measure the relative costs and benefits of managerial actions. We fill in this gap by using the estimates obtained from a dynamic model to quantify the effects of market timing on various firm policies. Structural estimation is particularly useful in this situation because misvaluation is, by nature, unobservable. The model allows us to deal with this challenge by putting enough plausible structure on the data for us to back out the effects of misvaluation.

Our baseline dynamic model captures decisions about a firm's dividends, investment, net cash (cash net of debt), equity issuances, and repurchases. Its backbone is a standard neoclassical model of physical and financial capital accumulation in the face of (1) uncertain profits, (2) constant returns to scale, (3) costs of adjusting the capital stock, and (4) underwriting costs in the equity market. The model then incorporates a new feature that is motivated by the behavioral finance literature. We allow for the market value of equity in the model to diverge from its true value, and this misvaluation can be persistent. 
Misvaluation affects the firm because it attenuates the extent to which equity issuances and repurchases cause dilution and concentration of long-term shareholders' shares. In response to misvaluation, firms predictably repurchase shares when equity is underpriced and issue shares when equity is overpriced. Model parameters then dictate the size of these equity transactions, as well as the size of the misvaluation shocks themselves. They also dictate whether the funds required for repurchases or received from issuances flow into or out of capital expenditures or net cash balances. Quantifying the relative magnitudes of these different effects therefore requires estimating the model's parameters. We use simulated method of moments (SMM), which matches model generated moments to real-data moments, that is, which minimizes model errors. We obtain estimates of parameters describing the firm's technology, equity market frictions, and most importantly, the variance and persistence of misvaluation shocks.

Briefly, we find that our model does a remarkably good job fitting many features of our data, given its simplicity. This good fit is evident not only in large heterogeneous samples of firms, but in homogeneous samples from several different industries. In addition, we obtain significant estimates of the variance and serial correlation of misvaluation shocks, and these shocks appear to be more important in industries a priori more likely to be subject to equity misvaluation. In short, we find that the model credibly captures those features of the data we wish to understand and shows that misvaluation shocks are important.

To understand how these shocks affect policies, we compute impulse response functions, which measure the responses of various policies to a one standard deviation profit shock or a one standard deviation misvaluation shock. We find that equity repurchases and issuances respond more strongly to the misvaluation shock than they do to the profit shock, but that these reactions are short lived. In contrast, we find that the strong response of net cash balances to the misvaluation shock takes four years to die out. Finally, we find that investment responds much more strongly to profit shocks than to misvaluation shocks.

Thus, our parameter estimates imply that although firms issue equity when equity is overvalued, they only use a small fraction of the proceeds for capital investment. Instead, they tend for the most part to hoard the proceeds as cash or to pay down debt. This saving then gives the firm 
more flexibility to repurchase shares when equity is undervalued or to respond to profit shocks by investing in capital goods. We conclude that although equity misvaluation appears important for financial policies, its impact on real policies is much smaller.

One advantage of structural estimation is that we can conduct counterfactual exercises, which extend the insights from the impulse response functions by considering hypothetical situations in which the magnitude and intensity of misvaluation shocks is different from that implied by our estimates. In particular, we compare a firm, as estimated, with a hypothetical firm that does not experience misvaluation shocks but that is otherwise identical. We find that average equity issuances and repurchases increase sharply with the variance of the misvaluation shocks. In addition, net cash balances also rise strongly. Although investment does not rise as sharply with the variance of misvaluation shocks, it stays above the level predicted by a frictionless investment model. Put simply, in the presence of misvaluation shocks, the firm overinvests, on average. Finally, we find that equity market timing increases intrinsic shareholder value by up to $8 \%$, relative to a model with no misvaluation shocks.

Our paper falls into several literatures. The first is the literature on structural estimation of dynamic models in corporate finance, such as Hennessy and Whited (2005, 2007), DeAngelo, DeAngelo, and Whited (2011), Morellec, Nikolov, and Schürhoff (2012), and Matvos and Seru (2011). These papers examine such issues as capital structure, financial constraints, agency problems, and corporate diversification. Our paper departs from these predecessors specifically by asking whether behavioral factors affect firm decisions.

Our paper also falls into the large empirical behavioral literature that has examined the effects of market misvaluation on firm policies. For example, Graham and Harvey (2001) find survey evidence that managers explicitly consider the possibility of equity overvaluation when deciding whether to issue shares. Eckbo, Masulis, and Norli (2007) and Baker and Wurgler (2012) provide excellent surveys of the empirical literature that has tested the more general proposition that market timing is important for many firm decisions. More recently, Jenter, Lewellen, and Warner (2011) find managerial timing ability by examining firms' sales of put options on their own stock, and Alti and Sulaeman (2011) find that high equity returns induce issuances only when there is institutional 
demand. Our results add to this literature by providing the first quantitative evaluation of the effects of misvaluation on firm policies.

The papers most closely related to ours are Bolton, Chen, and Wang (2012), Eisfeldt and Muir (2012), Yang (2011), and Alti and Tetlock (2011). The first two papers use models related to ours. However, neither attempts to estimate all of the model parameters or quantify any effects of misvaluation. Instead, Bolton, Chen, and Wang (2012) focuses on understanding the directional implications of mispricing and the comparative statics of risk management, and Eisfeldt and Muir (2012) focuses on the role of issuance costs in explaining aggregate financing correlations. Yang (2011) examines the theoretical implications for capital structure of mispricing that arises from differences in beliefs. Our goal, in contrast, is not to understand where mispricing comes from, but to quantify its effects empirically. Alti and Tetlock (2011) is similar to our work in that it also performs a structural estimation of a neoclassical investment model augmented to account for behavioral biases. However, Alti and Tetlock (2011) falls into the asset pricing literature that examines the effects of specific behavioral biases on asset returns. Our paper, in contrast, focuses on corporate finance issues.

The paper is organized as follows. Section 2 describes our data and presents descriptive evidence. Section 3 presents the model and discusses its optimal policies. Section 4 outlines the estimation and describes in detail our identification strategy. Section 5 presents the estimation results. Section 6 presents our counterfactuals, and Section 7 concludes. The Appendix contains proofs.

\section{Data and Summary Statistics}

Our data are from the 2011 Compustat files. Following the literature, we remove all regulated utilities (SIC 4900-4999), financial firms (SIC 6000-6999), and quasi-governmental and non-profit firms (SIC 9000-9999). Observations with missing values for the SIC code, total assets, the gross capital stock, market value, and net cash are also excluded from the final sample. As a result of these selection criteria, we obtain a panel data set with 55,726 observations for the time period between 1987 and 2010 at an annual frequency. We use this specific time period for two reasons. First, prior to the early 1980s, firms rarely repurchased shares, so these data are unlikely to help 
us understand repurchase policy. Second, because our model contains a constant corporate tax rate, we need to examine time periods in which tax policy is stable. Therefore, we start the sample just after the 1986 tax reforms. During this sample period there is only one major change in tax policy - the Jobs and Growth Tax Relief Reconciliation Act of 2003. Therefore, for some of our estimations, we consider two sample periods, before and after this legislation.

We define total assets as Compustat variable AT, the capital stock as GPPE, investment as capital expenditures (CAPX) minus sales of capital goods (SPPE), cash and equivalents as CHE, operating income as OIBDP, equity issuances as SSTK, equity repurchases as PRSTK, dividends as the sum of common and preferred dividends (DVC + DVP), debt as (DLTT + DLC), depreciation as DP, and Tobin's $q$ as the ratio of $\left(\mathrm{AT}+\mathrm{PRCC} \_\mathrm{F} \times \mathrm{CSHO}-\mathrm{TXDB}-\mathrm{CEQ}\right)$ to AT. All other variables are also expressed as fractions of total assets.

Purely suggestive evidence of a role for stock market mispricing in firm decision making is contained in Figures 1 and 2, which plot the yearly cross-sectional asset-weighted averages of several variables. Figure 1 plots the variables for small firms, and Figure 2 plots the variables for large firms. We define a firm as large in a particular year if its asset value exceeds the median for the sample in that year. Otherwise, we define a firm a small.

The top panels of Figures 1 and 2 plot equity issuance, equity repurchases, dividends, each of which is scaled by total book assets. They also plot a variable we refer to as "Return," which is the average annual real ex-dividend return on equity. The second panels of each of these two figures contains analogous plots for average debt issuance and saving, each of which is scaled by total assets, and the latter of which is defined as the change in (gross) cash balances. The third panels of each of these two figures contain analogous plots for investment scaled by assets.

We find several patterns of interest. In the top panels of these two figures we confirm the well-known stylized fact that equity returns and equity issuance track one another fairly closely, especially in the mid-1990s and the late 2000s. This pattern is much more pronounced for small firms than for large firms. We also see that repurchases appear to be slightly negatively correlated with returns. This pattern holds for both large and small firms. Finally, for both groups of firms, dividends are much smoother and decline over the sample period. 
In the second panels of each of Figures 1 and 2, the most striking result is the strong positive comovement between saving and equity returns, especially for the small firms. Interestingly we find almost no visible relationship between debt issuance and returns for the small firms, and perhaps a slightly negative relationship for the large firms. These results clearly indicate that any relationship between net cash changes and returns comes from the cash side rather than from the debt side. Finally, the third panels of these two figures shows that investment in physical assets is much smoother than equity returns and is, if anything, slightly negatively correlated with returns.

We have for the most part avoided interpreting these results because a correlation between equity returns and corporate policies might or might not indicate market timing. Market timing is important if equity values contain a component unrelated to the intrinsic value of the firm and if managers react to this misvaluation component. If this is the case, then the high correlations between equity transactions and returns are clearly consistent with timing. Further, if timing is indeed occurring, then the high positive correlation between saving and returns suggests that the funds to conduct equity transactions flow in and out of cash stocks. Of course, if equity is not misvalued or if managers do not pay any attention to misvaluation, these high correlations could also simply be a result of managers' attempts to fund profitable investment projects, which are naturally correlated with intrinsic firm value. To disentangle these competing explanations, we therefore estimate a dynamic model.

\section{Model}

This section presents the model. It then analyzes the optimality conditions and describes the optimal policies implied by the model solution.

\subsection{Model Components}

As a basis for our estimation we use a simple model that captures a firm's dividend, investment, cash (net of debt) and equity issuance/repurchase decisions in a dynamic setting. The model is based on a standard neoclassical model with financing frictions (e.g. Gomes 2001; Hennessy and Whited 2005). However, it deviates from this basic framework in two important ways. First, it 
contains a much richer specification of the payout process. Second, it incorporates a new feature that is motivated by the strand of the behavioral literature that studies equity misvaluation and investor sentiment. In particular, we allow for the market value of equity in the model to diverge from its true value. This divergence affects the cost of capital for the firm and therefore affects its real and financial decisions. We start by describing the firm's production technology. Then we move on to explain financing, taxation, and equity misvaluation.

We consider an infinitely lived firm in discrete time. At each time period the firm's risk-neutral manager chooses how much to invest in capital goods and how to finance these purchases. The firm is characterized by a constant returns to scale production technology, $z K$, that uses only capital, $K$, and that is subject to a profitability shock, $z$. The shock follows an $A R(1)$ in logs:

$$
\ln \left(z^{\prime}\right)=\mu+\rho_{z} \ln (z)+\varepsilon_{z}^{\prime}
$$

in which a prime denotes a variable in the next period, $\mu$ is the drift of $z, \rho_{z}$ the autocorrelation coefficient, and $\varepsilon_{z}$ is an i.i.d., random variable with a truncated normal distribution. It has a mean of 0 and a variance of $\sigma_{z}$.

Firm investment in physical capital is defined to be

$$
I=K^{\prime}-(1-\delta) K
$$

in which $\delta$ is the depreciation rate of capital. When the firm invests, it incurs adjustment costs, which can be thought of as profits lost as a result of the process of investment. These adjustment costs are convex in the rate of investment, and are given by

$$
A(I, K) \equiv \frac{\lambda I^{2}}{2 K}
$$

in which $\lambda$ is a parameter governing the curvature of the adjustment cost function.

If the firm were to maximize its expected present value, given the model ingredients thus far, we would have a neoclassical $q$ model of the sort formulated by Hayashi (1982) or Abel and Eberly 
(1994). In this type of model, external financing is implicitly frictionless. Thus, we will refer to this benchmark case as the "frictionless" case.

The model we study expands upon this frictionless case in two dimensions. The first is financing. We assume that the firm finances its investment activities by retaining its earnings, issuing debt, and issuing equity. When the firm retains earnings, it holds them as one-period bonds, denoted as $C$, that earn the risk-free rate, $r_{f}$. We allow $C$ to take both positive and negative values, with the latter indicating that the firm has net debt on its balance sheet. In the model debt is collateralized by the capital stock, so that the firm faces a constraint

$$
-C \leq \phi K
$$

in which $\phi$ represents the degree of collateral requirements. Thus, debt is risk-free and the interest rate on debt is $r_{f}$. Because we allow $C<0$, in what follows we refer to $C$ as net cash.

Equity issuances are denoted by $E$, with a negative number indicating repurchases. When the firm issues equity, it pays a proportional cost, $a_{1}$. This cost can be thought of as an intermediation cost for a seasoned offering. It can also be interpreted as a price concession the firm makes to the intermediary.

The firm's profits are taxed at a rate $\tau_{c}$, with the tax bill, $T$, given by

$$
T=\left(z K-\delta K+C r_{f}\right) \tau_{c}
$$

Note that the tax schedule is linear, so that the tax bill can be negative. This simplifying feature is intended to capture tax carryforwards and carrybacks. The final financing option available to the firm is adjustment of its level of dividends, $D$. These are given by a standard sources and uses of funds identity:

$$
D=z K-I-\frac{\lambda I^{2}}{2 K}+C(1+r)-C^{\prime}-T+E-a_{1} E \mathcal{I}(E>0)
$$

in which $\mathcal{I}(\cdot)$ is an indicator function. In words, this definition states that the cash flow net of taxes and equity issuance or repurchases equals the total dividend payout. We assume dividends are not 
taxed. ${ }^{1}$ This assumption implies that in the model as specified thus far, the firm is indifferent between paying dividends and repurchasing shares.

As this point the model is a standard neoclassical model of investment with financing and exogenous financing frictions. We now depart from this setting by allowing the firm to be subject to misvaluation shocks. First, let $V(K, C, \psi, z)$ denote the intrinsic value of the firm's equity, in which $\psi$ is the state variable denoting a misvaluation shock that affects observed ex-dividend equity values, $V^{*}$. In particular, $V^{*}$ is a stochastic multiple of ex-dividend intrinsic equity value:

$$
V^{*}=(V(K, C, \psi, z)-D) \psi
$$

The misvaluation shock, $\psi$, follows the first order autoregressive process:

$$
\ln \psi^{\prime}=\mu_{\psi}+\rho_{z \psi} \ln z+\rho_{\psi} \ln \psi+\varepsilon_{\psi}^{\prime} .
$$

Here, $\rho_{\psi}$ is the serial correlation of the shock, and $\varepsilon_{\psi}$ is a truncated normally distributed i.i.d. shock with mean zero and variance $\sigma_{\psi}$. This specification allows for correlation between the misvaluation and profitability processes. This correlation occurs through the $\rho_{z \psi}$ term, which implies that the current profitability level impacts the conditional expectation of the future misvaluation level. This model feature is motivated by the notion that investors over-extrapolate, so that overvaluation is more likely to occur in good times and undervaluation is more likely to occur in bad times. The $\mu_{\psi}$ term is set such that the unconditional expectation of the misvaluation term equals 1 . This calculation is detailed in the Appendix. When $\psi=1$, the firm is valued correctly; when $\psi<1$, the firm is undervalued, and when $\psi>1$, the firm is overvalued. We define the Markov transition function associated with (1) and (8) as $g\left(\varepsilon_{\psi}^{\prime}, \varepsilon_{z}^{\prime}, \mid \varepsilon_{\psi}, \varepsilon_{z}\right)$.

Four features of this misvaluation shock are important. First, the manager can observe the shock; that is, he knows the intrinsic value of the firm and can therefore observe deviations of intrinsic from market values. Market participants, however, either cannot observe intrinsic value or, as in Scheinkman and Xiong (2003), they disagree about fundamental value in such a way that

\footnotetext{
${ }^{1}$ Our estimation results are affected little by relaxing this assumption. See the Internet Appendix.
} 
optimal trading strategies result in mispricing. Second, our specification of an exogenous shock implies that managers do not manipulate market expectations about firm value. We discuss below the importance of this issue for our estimation results. Third, intrinsic equity value is a function not only of capital, net cash, and the profitability shock, but also of the misvaluation shock. The model solution implies that managers' optimal reactions to these shocks affect their decisions regarding net cash and capital, and thereby the intrinsic value of the firm. Finally, the misvaluation shock does not affect current period dividends given by (6).

\subsection{Shareholder Payout}

In a model in which firms can be misvalued, it is important to be precise about specifying the exact payoff to shareholders that the firm wishes to maximize. The total payoff includes dividends and net equity issuances. However, if we wish to think about market timing by managers, we cannot simultaneously maximize both components of the total payoff because market timing essentially involves a transfer to long-term shareholders from market participants who buy and sell shares with the firm. Therefore, we assume that the manager aims to maximize the payoff to a long-term investor that neither provides equity to the firm nor repurchases shares. The actual net payout to long-term shareholders is then the dividend stream, $D$.

\subsection{Dilution and concentration of holdings}

Because the manager maximizes the value of long-term shareholders, equity issuances and repurchases act to dilute and concentrate the dividend claims of long-term shareholders. We assume that the equity issuance or repurchase, $E$, is priced according to the current market value, $V^{*}$. The degree of dilution/concentration then depends on the misvaluation of the firm because managers attempt to engage in market timing by issuing or repurchasing equity when the firm is misvalued. This market-timing activity will create value for long-term shareholders. The degree of dilution/concentration equals:

$$
\frac{V^{*}}{V^{*}+E}=\frac{(V-D) \psi}{(V-D) \psi+E},
$$


where the degree of dilution for a given level of equity issuance (positive $E$ ) decreases as the level of misvaluation, $\psi$, increases. Symmetrically, the degree of concentration of dividend claims of long-term shareholders from repurchases (negative $E$ ) increases as the firm becomes increasing undervalued (as $\psi$ declines).

In the model thus far, nothing limits firms from engaging in very large equity transactions in response to misvaluation. However, market participants are likely to infer the size of the potential misvaluation from the relative size of the equity transaction. See, for example, the evidence in Brockman and Chung (2001). To capture this effect and thus to restrain the size of equity transactions, we assume that the size of the dilution/concentration is also affected by the size of the transaction scaled by the capital stock. The modified dilution/concentration ratio is then given by:

$$
\frac{V^{*}}{V^{*}+E+\nu(E, K)}=\frac{(V-D) \psi}{(V-D) \psi+E+\nu(E, K)}
$$

where $\nu(E, K)$ is a function that determines the degree of market reaction to the equity transaction. We assume that the market can have different reactions to repurchases and issuances and thus model $\nu(E, K)$ as

$$
\nu(E, K) \equiv \nu_{i}\left(\frac{E^{2}}{2 K}\right) \mathcal{I}(E>0)+\nu_{r}\left(\frac{E^{2}}{2 K}\right) \mathcal{I}(E \leq 0)
$$

We assume that $\nu_{i}>0$ and $\nu_{r}>0$, which implies that equity issuances create more dilution than they would otherwise and that equity repurchases create less concentration than they would otherwise. Both effects dampen the firm's incentives to react to misvaluation shocks.

\subsection{Value Maximization}

We can now write the valuation equation that managers wish to maximize as a Bellman equation, in which we take account the dilution/concentration of dividend claims that arises through equity issuance and repurchases. ${ }^{2}$ Let $\beta=\left(1+r_{f}\right)^{-1}$. Then the Bellman equation is

$$
V(K, C, \psi, z)=\max _{K^{\prime}, C^{\prime}, E}\left\{D+\beta \frac{(V-D) \psi}{(V-D) \psi+E+\nu(E, K)} \int V\left(K^{\prime}, C^{\prime}, \psi^{\prime}, z^{\prime}\right) d g\left(\varepsilon_{\psi}^{\prime}, \varepsilon_{z}^{\prime}, \mid \varepsilon_{\psi}, \varepsilon_{z}\right)\right\} .
$$

\footnotetext{
${ }^{2}$ Bazdresch (2005) uses a similar specification.
} 
The Bellman equation thus shows that the value of the firm for long-term shareholders, $V(K, C, \psi, z)$, equals the present value of dividends adjusted for dilution/concentration. The Bellman equation also reveals the intuition that the misvaluation shock affects the firm's discount rate, with overvaluation leading the manager to discount future cash flows using a higher discount factor. Further, this effect on discounting only operates when the manager is either issuing or retiring equity.

The relevant constraints in the maximization problem are the capital stock accumulation identity (2), the definition of dividends in (6), the collateral constraint in (4), and the following nonnegativity constraints

$$
K^{\prime} \geq 0, \quad D \geq 0
$$

It is not obvious that a solution to (11) exists, inasmuch as the discount factor need not always be less than one. However, the following proposition allows the Bellman equation (11) to be written with a constant discount factor.

Proposition 1 The solution to equation (11) is identical to the solution of

$$
V(K, C, \psi, z)=\max _{K^{\prime}, C^{\prime}, E}\left\{D-\frac{E}{\psi}-\frac{\nu(E, K)}{\psi}+\beta \int V\left(K^{\prime}, C^{\prime}, \psi^{\prime}, z^{\prime}\right) d g\left(\varepsilon_{\psi}^{\prime}, \varepsilon_{z}^{\prime}, \mid \varepsilon_{\psi}, \varepsilon_{z}\right)\right\} .
$$

It is straightforward to demonstrate that (12) satisfies the conditions necessary to prove existence and uniqueness in Stokey and Lucas (1989). It is worth noting that the Bellman equation (12) does not imply that the model contains stochastic issuance costs, as in Jermann and Quadrini (2012). Instead, the misvaluation shock directly affects the cost of equity capital and thus affects both repurchases and issuances. Further, the misvaluation shock has no impact on the budget constraint (6) that defines dividends, whereas stochastic issuance costs would.

\subsection{Constant returns to scale specification}

The problem can be further simplified by taking advantage of its constant returns to scale nature, and redefining all of the quantities in the model as a fraction of the capital stock, $K$. Define the 
following scaled variables:

$$
c \equiv \frac{C}{K}, d \equiv \frac{D}{K}, e \equiv \frac{E}{K}, i \equiv \frac{I}{K}, v(c, \psi, z) \equiv \frac{V(K, C, \psi, z)}{K}
$$

Then, by dividing all of the variables in (12) by $K$, and substituting (10) for $\nu(E, K)$, one obtains the following Bellman equation:

$v(c, \psi, z)=\max _{c^{\prime}, e, i}\left\{d-\frac{e}{\psi}-\frac{\nu_{i} e^{2} \mathcal{I}(e>0)}{2 \psi}-\frac{\nu_{r} e^{2} \mathcal{I}(e \leq 0)}{2 \psi}+\beta \int v\left(c^{\prime}, \psi^{\prime}, z^{\prime}\right)(1-\delta+i) d g\left(\varepsilon_{\psi}^{\prime}, \varepsilon_{z}^{\prime}, \mid \varepsilon_{\psi}, \varepsilon_{z}\right)\right\}$

and the constraints become

$$
\begin{aligned}
d-e+\mathcal{I}(e>0) a_{1} e & =z\left(1-\tau_{c}\right)-i-\frac{\lambda i^{2}}{2}+c\left(1+r-r \tau_{c}\right)-c^{\prime}(1-\delta+i)+\delta \tau_{c} \\
d & \geq 0 . \\
-c & \leq \phi .
\end{aligned}
$$

\subsection{Solution algorithm}

We use value function iteration to solve (13). The solution algorithm is conceptually simple. We can think of the firm as choosing the optimal value for next period investment and net cash, given the optimal allocation of the total payout into equity issuance/repurchases and dividends. Thus, given a particular choice for future net cash and investment, we solve for the optimal allocation of the payout using the first-order conditions of (13) and the nonnegativity constraint on dividends. Once we have the optimal allocations, we can then search over the optimal policies for next period investment and net cash.

We construct our simulated variables as follows. "Net cash" is $c$, "investment" is $i$, "net saving" is $c^{\prime}-c$, "equity issuance" is $\max (e, 0)$, "repurchases" are $\min (e, 0)$, and Tobin's $q$ is given by

$$
q \equiv \int \psi v\left(c^{\prime}, \psi^{\prime}, z^{\prime}\right)(1-\delta+i) d g^{\psi}\left(\varepsilon_{\psi}^{\prime}, \varepsilon_{\psi}\right) d g^{z}\left(\varepsilon_{z}^{\prime}, \varepsilon_{z}\right)
$$




\subsection{Optimal Policies}

We aim to estimate the model directly. However, identifying the model parameters and interpreting the estimation results require understanding the economic forces in the model. To this end, we first analyze the first-order conditions for optimal financial and investment policies.

\section{Equity and Dividends}

We start with equity and dividend policy, holding optimal investment and net cash policy fixed, which implies that the right side of (14) is also fixed. Let $e^{*}$ be the unconstrained best equity policy, that is optimal equity policy absent the constraint (15). We can solve for $e^{*}$ by substituting (14) into (13), differentiating with respect to $e$, and setting the result equal to zero.

$$
e^{*}= \begin{cases}\left(\left(1-a_{1}\right) \psi-1\right) / \nu_{i} & \text { for } \psi>1 /\left(1-a_{1}\right) \\ (\psi-1) / \nu_{r} & \text { for } \psi<1 \\ 0 & \text { for } 1 \leq \psi \leq 1\left(1-a_{1}\right)\end{cases}
$$

For $\psi$ sufficiently large, the firm wishes to issue equity, and for $\psi$ sufficiently small, the firm wishes to repurchase shares. The higher the parameters $\nu_{i}$ and $\nu_{r}$, the smaller the desired issuance and repurchasing activity. The linear issuance cost, $a_{1}$, induces an inaction range for $e^{*}$ in which the firm desires neither to issue nor to repurchase shares. Desired dividends then are given by (14).

Of course, these first order conditions ignore the constraint (15). If, absent this constraint, optimal dividends are positive, then the first order conditions in (18) hold exactly. On the other hand, if, absent this constraint, optimal dividends are negative, the constraint implies that they are zero. Optimal equity issuance is then given not by (18) but by (14).

These first order conditions imply a variety of different combinations of optimal equity and dividend policies. Table 1 contains a schematic that categorizes the various possibilities. For brevity, we denote the right side of the budget constraint (14) as $b$. Then we have:

$$
d-e+\mathcal{I}(e>0) a_{1} e=b
$$

The second column of Table 1 describes the equity policy given by (18) alone, that is, $e^{*}$. The third column lists various possibilities for the value of the budget constraint, $b$, relative to 0 and to $e^{*}$. 
Table 1: Optimal Equity and Dividend Policies

\begin{tabular}{|c|c|c|c|c|}
\hline & first order condition & budget constraint & equity policy & dividend policy \\
\hline (1) & $\psi<1, e^{*}<0$ & $b>-e^{*}$ & $e=e^{*}$ & $d=b+e>0$ \\
\hline (2) & $\psi<1, e^{*}<0$ & $0<b<-e^{*}$ & $e=-b$ & $d=0$ \\
\hline (3) & $\psi<1, e^{*}<0$ & $b<0$ & $e=-b /\left(1-a_{1}\right)>0$ & $d=0$ \\
\hline (4) & $\psi>1 /\left(1-a_{1}\right), e^{*}>0$ & $b>0$ & $e=e^{*}$ & $d=b+e\left(1-a_{1}\right)>0$ \\
\hline$(5)$ & $\psi>1 /\left(1-a_{1}\right), e^{*}>0$ & $-e^{*}\left(1-a_{1}\right)<b<0$ & $e=e^{*}$ & $d=b+e\left(1-a_{1}\right)>0$ \\
\hline (6) & $\psi>1 /\left(1-a_{1}\right), e^{*}>0$ & $b<-e^{*}\left(1-a_{1}\right)$ & $e=-b /\left(1-a_{1}\right)>0$ & $d=0$ \\
\hline (7) & $1<\psi<1 /\left(1-a_{1}\right), e^{*}=0$ & $b>0$ & $e=e^{*}=0$ & $d=b>0$ \\
\hline (8) & $1<\psi<1 /\left(1-a_{1}\right), e^{*}=0$ & $b<0$ & $e=-b /\left(1-a_{1}\right)>0$ & $d=0$ \\
\hline
\end{tabular}

The fourth and fifth columns list the optimal equity and dividend policies, respectively.

The first three cases describe undervaluation. If the firm has ample resources, as in case (1), then it simultaneously pays dividends and repurchases shares. Thus, the model allows for simultaneous dividends and share repurchases, even in the absence of institutional constraints on repurchases or tax motives. If the firm requires external equity funding $(b<0)$, as in case $(3)$, then it issues equity, even though equity is undervalued. Misvaluation in this case makes equity issuance extremely costly. Not only does the firm have to pay the issuance cost, $a_{1}$, but it is forced by the budget constraint to float shares in a state of the world in which it would be optimal to repurchase shares. As such, this case occurs very rarely in the estimated model. Case (2) is an intermediate case in which the firm has enough resources to repurchase shares, but not enough to attain the level given by $e^{*}$. Dividends are thus zero.

The next three cases describe overvaluation. If the right side of (14) is positive, as in case (4), then the firm issues equity, and then uses the proceeds, plus $b$ to pay dividends. (For our estimated sets of parameters, this situation rarely occurs.) If, as in case (5), $b<0$ but this deficit is more than filled by the level of equity issuance given by $e^{*}$, then once again, the firm both issues equity and pays dividends. If the firm is both overvalued and requires a great deal of external equity finance, as in case (6), then the firm issues equity but pays no dividends.

The final two cases concern the inaction region in which $e^{*}=0$. The firm never repurchases shares. If $b>0$, then the firm pays dividends and engages in no equity transactions. On the other hand, if $b<0$, the firm issues equity to fill the funding gap and then pays zero dividends. 


\section{Investment}

We now turn to the first order condition for optimal investment, which we obtain by differentiating (13) with respect to $i$ :

$$
(1+\gamma)(1+\lambda i)=\beta \int v\left(c^{\prime}, \psi^{\prime}, z^{\prime}\right) d g\left(\varepsilon_{\psi}^{\prime}, \varepsilon_{z}^{\prime}, \mid \varepsilon_{\psi}, \varepsilon_{z}\right)
$$

Here, $\gamma$ is the Lagrange multiplier on the dividend nonnegativity constraint (15). Naturally, this first order condition appears similar to that from a neoclassical $q$ model. If the dividend nonnegativity constraint does not bind, then the marginal cost of investment is $1+\lambda i$, and at an optimum it equals the discounted expected value of $v\left(c^{\prime}, \psi^{\prime}, z^{\prime}\right)$, which is the intrinsic value of the firm divided by the capital stock - roughly, average $q$. With financing frictions, the marginal cost of investment has two components. The first is the usual purchase and installation costs, $1+\lambda i$. The second is the Lagrange multiplier term $1+\gamma$, which implies that investment is more costly to the firm in those states of the world in which more investment would force the dividend nonnegativity constraint to bind.

Examining the marginal benefit of investment, given by the right side of (20), also reveals useful intuition. If the model contained no misvaluation shocks, the right hand side of (20) would be proportional to Tobin's $q$. However, in our model Tobin's $q$, as given by (17), is the expectation of market value, $\psi v(\cdot)$, and not of intrinsic value. Thus, (20) shows that investment depends on the expectation of intrinsic value and not on the expectation of market value. Misvaluation shocks affect investment only to the extent that they affect intrinsic value, that is, only to the extent that they create value for long-term shareholders.

\section{Net Cash}

Let $\xi$ be the Lagrange multiplier associated with the collateral constraint (4). The first order condition for net cash is given by

$$
1+\gamma+\xi=\beta \int v_{c}\left(c^{\prime}, \psi^{\prime}, z^{\prime}\right) d g\left(\varepsilon_{\psi}^{\prime}, \varepsilon_{z}^{\prime}, \mid \varepsilon_{\psi}, \varepsilon_{z}\right)
$$

The right side of (21) is expected discounted value of the shadow value of net cash. The first 
order condition then implies that net cash has more value to the firm in those states of the world in which the dividend constraint binds or in states of the world in which the collateral constraint binds. Therefore net cash has value because it confers financial flexibility. This intuition is standard in investment models augmented for financing (e.g. Hennessy and Whited 2005). The marginal cost of cash, as seen in (14) is taxation of interest. As in the case of investment, misvaluation does not affect optimal cash accumulation directly, but only through its effect on firm intrinsic value, $v(\cdot)$.

\section{Numerical Policy Functions}

To extend the model intuition, we plot in Figure 3 the policy functions for investment, net cash, issuances/repurchases, and dividends, which we denote as $\left\{c^{\prime}, i, e, d\right\}=h(c, \psi, z)$. Recall that a positive value for $e$ indicates an equity issuance, and a negative value indicates a repurchase. We parameterize the model using the first estimates reported subsequently in Table 2. (Policy functions

calculated with parameters from our other estimations are qualitatively similar.) Because estimate the model parameters, these policy functions can be interpreted as empirically relevant.

The top panel depicts the optimal choices of net cash, investment, equity issuances/repurchases, and dividends as a function of the misvaluation shock, so that the horizontal axis contains a range of possible values for the misvaluation shock. A value of 1 indicates no misvaluation. To construct the figure, we have fixed the profit shock at its mean value and fixed the current-period level of net cash at the sample mean from a model simulation.

As expected, given the first order conditions in (18), the equity policy function is upward sloping along the entire range of misvaluation shocks, with undervaluation resulting in repurchases, overvaluation resulting in issuance, and zero equity transactions occurring at the inaction range trigger, $1+a_{1}$. More interesting is the contrast between the policy functions for investment and net cash. The former is largely flat, turning slightly positive only for extremely high (and low probability) levels of overvaluation. In contrast, the policy function for net cash is upward sloping along the entire range of possible levels of misvaluation. Low levels of misvaluation result in net debt (negative net cash) and high levels result in positive net cash. This contrast occurs because investment is costly to adjust. Thus, the firm funnels equity proceeds into cash instead of investment 
because the financial flexibility benefit of cash outweighs the net-of-adjustment-costs benefit of an extra unit of capital. Finally, the policy function for dividends is also flat, except for a slight uptick for extreme overvaluation. This pattern can also be understood in terms of cases (4) and (5) in Table 1, in which desired equity issuance is so high that there are proceeds left over to distribute to shareholders after all other optimal policies have been funded.

Taken together, the main conclusions we can draw from examining these policy functions is that misvaluation shocks have only modest effects on investment and dividend policy, but strong effects on equity issuance, equity repurchase, and net cash policy. It is worth noting that these patterns are in no way hardwired into the model. For example, the finding of a response of any variable to misvaluation shocks comes from our ability to estimate a substantial variance for the misvaluation shock. Similarly, the modest response of investment comes from our estimation of substantial investment adjustment costs, which discourages firms from adjusting on this margin.

The next panel depicts the response of investment, net cash, issuances/repurchases, and dividends to the profitability shock, $z$. For this panel, we have fixed the level of $\psi$ at 1 and fixed the current-period level of net cash at the sample mean from a model simulation. In contrast to the result in the first panel, investment responds strongly and positively to the profitability shock, which makes sense, given that the profitability shock is the one-period marginal product of capital. Net cash is negative over the range of profitability shocks, which makes sense, given that this policy function is from an estimated model, and given that one of the features used to estimate the model is negative net cash (positive net debt). The response of optimal net cash to the profitability shock is nonmonotonic. For low levels of the shock, the increase in the marginal product of capital implies that the firm substitutes physical assets for financial assets, and net cash declines. For intermediate levels of $z$, the income effect from higher $z$ dominates the previously described substitution effect, and both investment and net cash rise. For extremely high (and unlikely) levels of the $z$ shock, the flexibility benefit of higher net cash (lower net leverage) is negligible because the firm is flush with resources. Thus, the firm increases net leverage to reap the tax benefit.

Equity transactions vary little with the profitability shock. Indeed, the firm uses external equity financing only for low levels of the profitability shock, which correspond to states of the world in 
which it does not have enough resources to fund its optimal investment program. Dividends do respond to the profitability shock, but only when the profitability shock is high. In these states of the world, the firm does not wish to repurchase shares (because $\psi=1$ ), and it has more than enough internal funds to finance its optimal investment program, so it pays the residual out to shareholders.

The main conclusions to be drawn from Figure 3 are as follows. First, investment is mostly affected by shocks to profitability and not by equity market misvaluation. Second, net cash policy appears to respond to both profitability and misvaluation shocks, but the reasons are different. The response to profitability shocks results from firms preferring to use internal funds or debt financing for investment in the face of costly external equity finance. The response of net cash to misvaluation shocks happens because investment adjustment costs discourage firms from adjusting investment. Finally, equity issuance policy is affected far more by misvaluation shocks than by profitability shocks.

\section{Estimation and Identification}

In this section, we explain how we take the model derived in Section 2 to the data. We first outline the estimation procedure. We then discuss our identification strategy.

\subsection{Estimation}

We estimate most of the structural parameters of the model using simulated method of moments. However, we estimate some of the model parameters separately. For example, we estimate the risk-free interest rate, $r_{f}$, as the average real 3-month Treasury bill rate over the sample period of interest. We set the corporate tax rate equal to $20 \%$. This level is lower than the statutory rate because we have omitted personal taxes on distributions and interest from the model.

We then estimate the following 11 parameters using simulated method of moments: the equity issuance cost parameter, $a_{1}$; the drift, standard deviation, and autocorrelation of the profitability

process, $\mu, \sigma_{z}$ and $\rho_{z}$; the quadratic adjustment cost parameter, $\lambda$; the standard deviation and autocorrelation of the misvaluation process, $\sigma_{\psi}$ and $\rho_{\psi}$; the market-timing penalties, $\nu_{i}$ and $\nu_{r}$, the 
correlation between the misvaluation and profitability shocks, $\rho_{z \psi}$, and the depreciation rate, $\delta$.

Simulated method of moments, although computationally cumbersome, is conceptually simple. First, we generate a panel of simulated data using the numerical solution to the model. Specifically, we take a random draw from the distribution of $\left(\varepsilon_{z}^{\prime}, \varepsilon_{\psi}^{\prime}\right)$, conditional on $\left(\varepsilon_{z}, \varepsilon_{\psi}\right)$, and then compute $v(c, \psi, z),\left(c^{\prime}, e, i\right)=h(c, \psi, z)$, and various functions of $v(c, \psi, z), c^{\prime}, e$, and $i$, such as Tobin's $q$. We continue drawing values of $\left(\varepsilon_{z}^{\prime}, \varepsilon_{\psi}^{\prime}\right)$ and using these computations to generate an artificial panel of firms. Next, we calculate interesting moments using both these simulated data and actual data. The objective of SMM is then to pick the model parameters that make the actual and simulated moments as close to each other as possible.

The next issue in SMM is whether to match moments using an identity matrix or a weight matrix based on the moment covariances. Using an identity matrix implicitly puts the most weight on the moment that is the largest in absolute value. Because the size of a moment rarely corresponds to a relevant economic or statistical objective, we match moments using the inverse of the covariance matrix of the moments. Roughly speaking, this scheme puts the most weight on the most precisely estimated moments, which is a sensible statistical objective. See the Appendix for details.

One final issue is unobserved heterogeneity in our data from Compustat. These firms differ along a variety of dimensions, such as technology and access to external finance. In contrast, our simulations produce i.i.d. firms, with the only source of heterogeneity being the individual draws of $\left(\varepsilon_{z}, \varepsilon_{\psi}\right)$. Therefore, in order to render our simulated data comparable to our actual data, we can either add heterogeneity to the simulations, or remove the heterogeneity from the actual data. We opt for the latter approach, using fixed firm effects in the estimation of variances and covariances. We calculate autocorrelation coefficients using the method in Han and Phillips (2010), which controls for heterogeneity at the firm level.

This issue of heterogeneity implies that SMM estimates the parameters of an average firm—not the average of the parameters across firms. These two quantities are not the same because the model is nonlinear. Because it is often difficult to conceptualize an average firm in a large population of firms over a long time span, we first examine subsamples of firms that are homogeneous along two dimensions. In particular, Figures 1 and 2 indicate that small firms are different in important ways 
from large firms, and 1980s and 1990s are different from the 2000s. We therefore analyze four separate groups of firms. We examine separately the time periods before and after the Jobs and Growth Tax Relief Reconciliation Act of 2003. Within these two time periods we then analyze small and large firms, so that we end up with four groups of firms.

\subsection{Identification}

The success of this procedure relies on model identification. Global identification of a simulated moments estimator obtains when the expected value of the difference between the simulated moments and the data moments equal zero if and only if the structural parameters equal their true values. A sufficient condition for identification is a one-to-one mapping between the structural parameters and a subset of the data moments of the same dimension. Because our model does not yield such a closed-form mapping, we take care to choose moments that are sensitive to variations in the structural parameters such as the adjustment cost parameter, $\lambda$. On the other hand, we do not "cherry-pick" moments. Instead, we examine the mean, variance, and serial correlation of all of the variables we can compute from our model: investment, profits, equity issuances, equity repurchases, net cash, equity returns, and Tobin's $q$.

We now describe and rationalize the 19 moments that we match. Of particular interest is finding moments to identify the variance and serial correlation of the misvaluation shock, $\rho_{\psi}$ and $\sigma_{\psi}$, as well as the correlation between the two shocks, $\rho_{z \psi}$. Because of the feedback in the model from misvaluation to firm investment and financing decisions, this task is difficult. This task is also difficult because both the misvaluation shocks and profitability shocks affect firm policies, so it is necessary to disentangle the effects of the two shocks.

Of great help in this endeavor are the mean, variance and serial correlation of operating profits, which are defined in the model as $z$. The only model parameters that induce any variation in these three moments are the drift, residual standard deviation, and serial correlation of the profitability shock, $\mu, \sigma_{z}$, and $\rho_{z}$. Therefore, these three parameters can be pinned down using only these three moments. Roughly speaking, with these three parameters pinned down, moments related to the market value of the firm can be used to pin down $\rho_{\psi}, \sigma_{\psi}$, and $\rho_{z \psi}$. 
We use six moments related to market values. The first five are the mean, variance, and serial correlation of Tobin's $q$, and the variance and serial correlation of equity returns, which we define as $\left(\psi^{\prime} v^{\prime}\right) /(\psi v)-1$. Because changes in almost all of the model parameters induce significant changes in firm value, the mean of Tobin's $q$ ends up being a "catch-all" identifying moment. The variance and serial correlation of Tobin's $q$ are more useful for specifically identifying the variance and the serial correlation of the misvaluation process, $\sigma_{\psi}$ and $\rho_{\psi}$. Intuitively, one would expect these two moments to be strongly increasing in these two parameters, and this intuition holds true for a wide variety of model parameterizations. Although the variance and serial correlation of equity returns are also useful for identifying these two parameters (for the same reason), the serial correlation of returns is also useful for identifying $\rho_{z \psi}$. In this case, for most plausible parameter values, $\rho_{\psi}$ is increasing in this moment, whereas, $\rho_{z \psi}$ is decreasing. These opposite effects allow us to separate the effects of $\rho_{\psi}$ and $\rho_{\psi z}$ on the model. The sixth moment we use to identify misvaluation shocks is the slope coefficient from regressing equity issuance on returns, which is generally increasing in $\rho_{z \psi}$, but decreasing in $\sigma_{z}$. This latter result occurs because the variance of returns is in the denominator of the regression coefficient.

Our next moments are the mean, serial correlation, and variance of the rate of investment, $i$. The variance is useful for identifying the adjustment cost parameter, $\lambda$, because higher $\lambda$ produces less volatile investment. The serial correlation is primarily affected by the smooth adjustment cost parameter but also by the serial correlation of the profitability process, $\rho_{z}$. The mean of investment is particularly useful for identifying the depreciation rate of capital, as average investment is strongly increasing in this parameter.

The rest of the moments pertain to the firm's financing decisions. We include the mean, serial correlation, and variance of the ratio of net cash to assets. We also include the mean and variance of the ratio of equity issuance to capital and the mean and variance of the ratio of repurchases to capital. These last four moments are useful for identifying the equity issuance cost parameter, $a_{1}$, and the parameters penalizing equity transactions, $\nu_{i}$ and $\nu_{r}$. The issuance penalty parameter, $\nu_{i}$ is also in part identified by the coefficient from regression issuance on returns because this coefficient falls sharply as $\nu_{i}$ rises. 


\section{$5 \quad$ Results}

We first present estimates on samples of large and small firms. We then present an estimation in which we attempt to disentangle our misvaluation shocks from those that might be induced by a pricing kernel. Finally, we examine model estimations that use data from different industries.

\subsection{Baseline Estimation}

Table 2 shows that the model fits the data surprisingly well. The top panel shows the actual and simulated moments for each of our four subsamples, with t-statistics in parentheses under the simulated moments. Across the four estimations approximately half of the simulated moments are statistically significantly different from their data counterparts, but only a handful are economically different. This good fit is remarkable, given that we have used almost twice as many moments as parameters in the estimation. In comparison to previous studies in corporate finance that use SMM, our model is overidentified by many more degrees of freedom. The model does a particularly good job in matching all moments related to net cash, the mean of investment, the mean and variance of profits, the variance and serial correlation of returns, and the variances of equity issuances and repurchases. In particular, the model comes close to matching the high net cash of the small firms in the latter part of the sample. The model does a fair job of matching such moments as the means of equity issuance and repurchases, as well as several of the serial correlations. The model struggles with only two features of the data: the variances of investment and the variance of Tobin's $q$. The simulated investment variance is too small, and the simulated Tobin's $q$ variance for the samples of small firms is too large.

It is worth noting that we omit moments related to dividends. As is the case with all investmentbased models of financing (e.g. Hennessy and Whited 2005, 2007), the model implied variance of dividends far exceeds the smoothness observed in the data. Therefore, even though including these moments in the estimation matters only slightly for the parameter estimates, including them does matter for model fit. ${ }^{3}$ Not only does the model fail to match moments related to dividends, but it does a much poorer job of matching other moments. This failure to match important features of

\footnotetext{
${ }^{3}$ See the Internet Appendix for details.
} 
the data implies that any counterfactuals constructed using the poorly fitting simulated moments are likely to produce inaccurate inferences. We therefore prefer to omit the mean and variance of dividends from our moment list.

The bottom panel of Table 2 presents the parameter estimates we obtain from each of our four samples. Most of the parameters are statistically significant. The exceptions are three of the estimates of $a_{1}$, the issuance cost parameter. For the late period, this result is not surprising, given the rise of the practice of shelf registration of equity offerings (Gao and Ritter 2011). For the early period, this parameter is only insignificant for the large firms.

More importantly, for all four samples, the standard deviation and serial correlation of the misvaluation shocks are highly statistically significant. The estimates of the standard deviation range from 0.35 to 0.45 , and the estimates of the serial correlation range from 0.42 to 0.68 . These estimates seem large at first glance. However, in interpreting these magnitudes, it is important to remember what misvaluation shocks represent in the model. They are any movement in market prices that the manager views as deviations from fundamental firm value. Thus, our model is picking up a great deal of variability that is not strictly mispricing in the sense of Scheinkman and Xiong (2003) or Gilchrist, Himmelberg, and Huberman (2005). In addition, it is important to remember that these figures are for the driving process of $\ln (\psi)$-not the level of $\psi$. Thus, the standard deviation estimates are roughly comparable to return standard deviations, which for individual companies often exceed $50 \%$. We conclude that a great deal, but by no means all, of the variability in market values fails to reflect the manager's view of fundamentals.

The economic magnitudes of many of the other parameters are plausible. For example, the estimates of $\delta$ correspond to the average ratio of investment to assets seen in Compustat data, and the adjustment cost parameters correspond to the range of estimates of the coefficient on Tobin's $q$ reported in, for example, Erickson and Whited (2012). The two parameters that are difficult to interpret are $\nu_{i}$ and $\nu_{r}$. To start, we note that these quadratic terms change the effective cost of issuance and repurchases. Thus, one way to interpret these parameters is in terms the amount of issuance it would take in the absence of these parameters to deliver the amount of dilution or concentration that occurs, given the estimated values of $\nu_{i}$ and $\nu_{r}$. These figures are 
reasonable. For example, according to the early-small estimation, an equity issuance of $1 \%$ of firm value has a dilution effect for long-term shareholders equal to an issuance of $1.07 \%$ of firm value in a frictionless setting with no $\nu_{i}$ term. These dilution effects range from $1.14 \%$ to $1.11 \%$ for the other three samples. The figures for repurchases imply concentration of long-term shareholders by values ranging from $0.88 \%$ to $0.95 \%$ for a $1 \%$ equity repurchase. In sum, although we find large amounts of perceived misvaluation, these parameter estimates indicate that managers are cautious to respond to them due to potential adverse market responses.

\subsection{Pricing Kernel}

We now ask whether our model is just picking up the effects of risk. Otherwise, we cannot rule out the interpretation that our model captures movements in equity values that are induced by time varying expected returns rather than by misvaluation. To address this concern, we add an aggregate productivity term to our model that is calibrated to match the duration and severity of expansions and recessions in the United States and an associated pricing kernel. See the Appendix for details. Table 3 presents our estimates of this augmented model. Interestingly, the model fit is slightly worse. In addition, the estimates of the standard deviation and serial correlation of the misvaluation shocks are nearly identical to those reported in Table 2. Thus, we conclude that our estimates of misvaluation parameters are not simply reflecting time-varying expected returns.

\subsection{Industry Estimation}

As noted earlier, the parameter estimates we obtain are for an average firm - not the average parameter across firms. Therefore, it makes sense to estimate the model on relatively homogeneous groups of firms. Although our stratification of the sample into early and late periods and small and large firms does accomplish this goal to some extent, we are nonetheless mixing firms from different industries in the same estimation. To address this issue, we estimate the model on subsamples of firms stratified by two-digit SIC industry. This exercise is useful in that it provides a stricter test of the model's ability to rationalize the data from very different types of firms.

Because our highly nonlinear estimations require a great deal of data for identification, we choose the eight two-digit industries with the most data points. SIC13 is oil and gas extraction; 
SIC20 is food products; SIC28 is chemicals and allied products; SIC35 is machinery and computer equipment; SIC26 is electronic and electrical equipment; SIC38 is measuring instruments; SIC50 is wholesale trade; and SIC73 is business services.

We first present the moment estimates. For brevity, we present in Figure 4 our results from matching an important subset of moments: the "mean" moments, which are the easiest to interpret. Each panel of Figure 4 corresponds to a different moment, with the horizontal axes containing the simulated moments and the vertical axes containing the data moments. Each pair of data moment and corresponding simulated moment is then labeled by the relevant industry SIC code.

The first four panels show that the model does an excellent job of matching average net cash, investment, operating profit, and Tobin's $q$. All of these moment pairs line up nicely along their respective $45^{\circ}$ lines, and only four of these pairs represent significant differences. This result is particularly strong, given the large differences in the moments across industries. For example, oil and gas extraction has high net debt of approximately $25 \%$ of assets, and business services has high net cash of approximately $5 \%$ of assets. The model does not do as good a job matching average equity issuance and average repurchases, with simulated equity issuances slightly low and simulated repurchases slightly high. Nonetheless, the model can capture the broad range of issuances and repurchases seen in the data. In the language of asset pricing, the model captures the "spread" observed in these different moment conditions.

Table 4 contains the parameter estimates. We concentrate on the estimates of the standard deviation and serial correlation of the process for the misvaluation shock. The industries with the lowest variance shocks are SIC20 (food products) and SIC50 (wholesale trade). The industries with the highest variance shocks are SIC13 (oil and gas extraction), SIC35 (machinery and computer equipment), SIC38 (instruments), and SIC73 (business services). It is useful to compare these estimates with other measures of misvaluation. Unfortunately, misvaluation of an entire group of firms is hard to gauge. Nonetheless, we find it plausible that firms in high R\&D industries are more opaque, and thus more likely to suffer from misvaluation. The last line of Table 4 contains average R\&D for the firms in each industry. Interestingly, the lowest R\&D industries (food and wholesale) also have the lowest variance misvaluation shocks, and except for oil and gas extraction, which does 
negligible $R \& D$, the highest $R \& D$ industries also have the highest variance misvaluation shocks. One obvious explanation for the oil and gas industry is that the exploration business is extremely risky and the oil reserves of these companies are hard to value. This result thus constitutes a useful external model validation exercise that lends credibility to the interpretation of $\psi$ as a misvaluation shock, as opposed to some other source of variability.

\section{Counterfactuals}

One particularly useful way to quantify the effects of misvaluation is via counterfactual exercises. First, we use comparative statics to measure how much average firm variables change when we alter the parameters that govern the misvaluation shock process. The results from these exercises are in Figure 5. To construct this figure, we parameterize the model according to the early-small estimates in Table 2. We then solve the model 20 times, each time corresponding to a different value of $\sigma_{\psi}$, with the rest of the parameters held at their estimated values. Each time we solve the model, we simulate 150,000 firm/year observations, and then compute the averages of five variables.

In the top panel we plot repurchases and equity issuance as a function of the misvaluation shock standard deviation, $\sigma_{\psi}$. Not surprisingly, equity issuances and repurchases are increasing in the misvaluation shock standard deviation. In other words, firms in environments in which there is more misvaluation conduct more equity transactions, on average.

In the middle panel we plot average net cash and average investment as a function of the shock standard deviation. We find that net cash is much higher for firms that face higher standard deviation misvaluation shocks. Although average investment is also higher, this effect is much more modest. For reference we also plot the level of investment that would result from a frictionless neoclassical investment model with the same profitability shock process, depreciation rate, and investment adjustment costs. Interestingly, we find that firms overinvest relative to this level, except at the lowest misvaluation shock volatility. This result is interesting because in the model misvaluation shocks allow firms to issue equity when the existence of equity issuance costs would make this source of financing prohibitively expensive, that is, misvaluation alleviates finance constraints.

Our estimates imply that this effect does not result in the same level of investment that would 
occur in a frictionless environment. Instead, the resulting level of investment that is much higher.

The bottom panel plots average intrinsic firm value, $v$ as a function of $\sigma_{\psi}$. The effect of the misvaluation shock standard deviation on intrinsic value is modest, especially for low shock standard deviations. One question we can answer from this plot is how much intrinsic value would be lost if we were to drop the shock standard deviation to zero from its estimated value of 0.37 . We find that a firm would lose $8.9 \%$ of long-term shareholder intrinsic value. ${ }^{4}$ This figure is likely an upper bound for the actual amount of lost value. When we change the misvaluation shock standard deviation, we do so holding all other parameters constant. However, it is unlikely that the market response to equity issuance and repurchases (as captured by the parameters $\nu_{i}$ and $\nu_{r}$ ) would remain the same in a low misvaluation environment. Indeed, these parameters would likely be somewhat smaller and equity transactions would be less constrained. More liberal equity policies would then attenuate the drop in intrinsic value.

To understand the economic mechanisms behind this result, we examine the immediate impact of misvaluation shocks by calculating impulse response functions. Once again, we parameterize the model using the estimates from the small firms in the early period. This exercise differs from our comparative statics exercises in which we change a model parameter and then examine the impact on average firm policies. Instead, here we are looking at the immediate response of a single variable to an actual realization of a shock. Calculating an impulse response function with real data requires estimating, inverting, and orthogonalizing a vector autoregression because the shocks that drive the variables of interest are unobservable. However, in our simulated data we do observe our shocks, so to calculate our impulse response functions, we simply regress our variables of interest on each of our two shocks, which we standardize and orthogonalize using a Cholesky decomposition.

The results are in Figure 6. The vertical axis in each plot contains the change in the variable of interest in response to a one standard deviation shock. The horizontal axis is time since the shock realization. The most striking result is in the top panel, which depicts net cash balances. A one standard deviation misvaluation shock raises net cash balances from their average level of approximately -0.12 by 0.05 to approximately -0.07 . This substantial effect dies out only slowly

\footnotetext{
${ }^{4}$ The corresponding figures for our other three samples are between $5.2 \%$ and $7.1 \%$.
} 
over the course of five years. The obvious conclusion from this exercise is that misvaluation shocks help ease financial constraints by allowing firms to accumulate cash (pay down debt). The effects of a one standard deviation misvaluation shock are also noticeable on issuances, but to a much lesser extent on dividends, repurchases, and especially investment. In addition, all of these effects die out much more quickly than does the effect on net cash.

The effects of the profit shock are noticeably different in magnitude. First, a one standard deviation profit shock increases average cash balances, but the effect is less that the effect of a misvaluation shock. The intuition is is that a positive profit shock has an income effect on all firm assets, both productive assets and net financial assets. Next, we find that while issuance and repurchases respond to the profit shocks, these responses are much smaller in magnitude than the responses to the misvaluation shock. In contrast, profit shocks have a much stronger effect on investment and dividends than do misvaluation shocks.

Finally, we conduct an informal "out-of-sample" test of the validity of the model, in the sense that we want to ascertain whether the model can reconcile patterns in the data that were not used to estimate it. In particular, given our interest in market timing, we want to ascertain whether our model can replicate the correlations between equity returns and a variety of different variables. Table 5 contains the results from this comparison. We do separate calculations for the four samples from Table 2: early/small, early/large, late/small, and late/large. The actual data correlations are correlations between the aggregate variables depicted in Figures 1 and 2. The simulated correlations are from data simulated from the model, given the four different parameterizations.

The striking result is for all four samples, we match the signs of the correlations between returns and each of investment, net saving, equity issuance, and repurchases. For the two early samples, we also match many of the actual magnitudes of the correlations. Our model struggles more with matching the large magnitude of the correlations from the latter part of the sample; however, these magnitudes are primarily driven by the crisis. Our model does not do as good a job at matching the signs of the correlations between returns and dividends, which is not surprising because we have no moments related to dividends in our model. Nonetheless, given that we only use one out of these five correlations (returns versus issuance) to estimate our model, our ability to replicate 
other correlations bolsters confidence in the model.

\section{Conclusion}

This paper quantifies the extent to which nonfundamental movements in the price of a firm's stock affect its various policies. Although this topic has been addressed by a large number of studies, we approach the problem in a new way - structural estimation - with the intent of adding quantitative results to this body of literature. We estimate a version of a constant returns neoclassical investment model in which equity financing is costly, the firm can accumulate cash and issue debt, and, most

importantly, equity values can be subject to misvaluation shocks. In the model, firms naturally issue equity when it is overvalued and repurchase equity when it is undervalued. Depending on the model parameters, the funds flowing to and from these activities can come from either changes in (net) cash balances or changes in investment.

We produce several findings. First, we find that non-fundamental movements in equity prices (misvaluation) are large. Our counterfactual exercises show that firms do issue equity and repurchase equity in response to misvaluation shocks, but the proceeds from these issuances and the funds from these repurchases flow into and out of net cash balances. The immediate impact on real investment expenditures is small. This result echoes the descriptive findings in McLean (2011) that firms tend to hoard the proceeds of SEOs. These higher net cash balances allow firms more financial flexibility, which in turn adds to intrinsic shareholder value. In short, misvaluation has large effects on financial policies, much smaller effects on real investment policies, and modest valuation effects.

One admitted drawback of our approach is our modeling of misvaluation shocks as exogenous. This modeling choice is necessary for tractability, and this tractability allows us to examine the interesting question of market timing quantitatively. However, this choice makes it difficult to answer questions related to managers' manipulation of share prices. If managers do attempt to misguide shareholders, then their reactions to mispricing might differ from those produced by our model. Examining this type of framework might be an interesting avenue for future research. 


\section{References}

Abel, Andrew B., and Janice C. Eberly, 1994, A unified model of investment under uncertainty, American Economic Review 84, 1369-1384.

Alti, Aydoğan, and Johan Sulaeman, 2011, When do high stock returns trigger equity issues?, Journal of Financial Economics 103, 61-87.

Alti, Aydoğan, and Paul Tetlock, 2011, How important is mispricing?, Manuscript, Columbia University.

Baker, Malcolm, and Jeffrey Wurgler, 2012, Behavioral corporate finance: An updated survey, in George Constantinides, Milton Harris, and Réne Stulz, ed.: Handbook of the Economics of Finance . vol. 2 (Elsevier: North-Holland).

Bazdresch, Santiago, 2005, Financial lumpiness and investment, Manuscript, University of Minnesota.

Bolton, Patrick, Hui Chen, and Neng Wang, 2012, Market timing, investment, and risk management, Journal of Financial Economics forthcoming.

Brockman, Paul, and Dennis Y. Chung, 2001, Managerial timing and corporate liquidity: evidence from actual share repurchases, Journal of Financial Economics 61, 417-448.

DeAngelo, Harry, Linda DeAngelo, and Toni M. Whited, 2011, Capital structure dynamics and transitory debt, Journal of Financial Economics 99, 235-261.

Duffie, Darrell, and Kenneth J Singleton, 1993, Simulated moments estimation of markov models of asset prices, Econometrica 61, 929-52.

Eckbo, B. Espen, Ron W. Masulis, and Oyvind Norli, 2007, Security offerings, handbook of corporate finance: Empirical corporate finance, e. eckbo, in B. Espen Eckbo, ed.: Handbook of Corporate Finance: Empirical Corporate Finance (Elsevier: Amsterdam).

Eisfeldt, Andrea, and Tyler Muir, 2012, Aggregate issuance and savings waves, manuscript, UCLA.

Erickson, Timothy, and Toni Whited, 2002, Two-step gmm estimation of the errors-in-variables model using high-order moments, Econometric Theory 18, 776-799.

Erickson, Timothy, and Toni M. Whited, 2012, Treating measurement error in Tobin's q, Review of Financial Studies.

Gao, Xiaohui, and Jay Ritter, 2011, The marketing of seasoned equity offerings, Journal of Financial Economics 97, 33-52.

Gilchrist, Simon, Charles P. Himmelberg, and Gur Huberman, 2005, Do stock price bubbles influence corporate investment?, Journal of Monetary Economics 52, 805 - 827.

Gomes, Joao F., 2001, Financing investment, American Economic Review 91, 1263-1285.

Graham, John R., and Campbell R. Harvey, 2001, The theory and practice of corporate finance: Evidence from the field, Journal of Financial Economics 60, 187-243.

Han, Chirok, and Peter C. B. Phillips, 2010, GMM estimation for dynamic panels with fixed effects and strong instruments at unity, Econometric Theory 26, 119-151.

Hayashi, Fumio, 1982, Tobin's marginal q and average q: A neoclassical interpretation, Econometrica 50, 213-224. 
Hennessy, Christopher A., and Toni M. Whited, 2005, Debt dynamics, Journal of Finance 60, $1129-1165$.

- 2007, How costly is external financing? Evidence from a structural estimation, Journal of Finance 62, 1705-1745.

Ingram, Beth F., and Bong-Soo Lee, 1991, Simulation and estimation of time series models, Journal of Econometrics 47, 197-205.

Jenter, Dirk, Katharina Lewellen, and Jerold B. Warner, 2011, Security issue timing: What do managers know, and when do they know it?, Journal of Finance 66, 413-443.

Jermann, Urban, and Vincenzo Quadrini, 2012, Macroeconomic effects of financial shocks, American Economic Review, forthcoming.

Matvos, Gregor, and Amit Seru, 2011, Resource allocation within firms and financial market dislocation: Evidence from diversified conglomerates, manuscript.

McLean, R. David, 2011, Share issuance and cash savings, Journal of Financial Economics 99, 693 -715 .

Morellec, Erwan, Boris Nikolov, and Norman Schürhoff, 2012, Corporate governance and capital structure dynamics, Journal of Finance 67, 803-848.

Scheinkman, Jose A., and Wei Xiong, 2003, Overconfidence and speculative bubbles, Journal of political Economy 111, 1183-1220.

Shiller, Robert J., 1981, Do stock prices move too much to be justified by subsequent changes in dividends?, The American Economic Review 71, 421-436.

Stokey, Nancy L., and Robert E. Lucas, 1989, Recursive Methods in Economic Dynamics (Harvard University Press: Cambridge, MA).

Yang, Baozhong, 2011, Capital structure with heterogeneous beliefs and market timing, Manuscript, Georgia State University. 


\section{Appendix}

This appendix contains the proof of Proposition 1, the derivation of $\mu_{\psi}$, the model that contains time-varying expected returns, and an outline of the estimation procedure.

\section{Proof of Proposition 1}

Let $\tilde{V}$ be a solution to equation (11), with corresponding policy functions $\tilde{D}$ and $\tilde{E}$. Then one obtains from (11):

$$
\tilde{V}(K, C, \psi, z)=\tilde{D}+\beta \frac{\psi(V-\tilde{D}(1-\tau))}{\psi(V-\tilde{D})+\tilde{E}+\nu(\tilde{E}, K)} \int V\left(K^{\prime}, C^{\prime}, \psi^{\prime}, z^{\prime}\right) d g\left(\varepsilon_{\psi}^{\prime}, \varepsilon_{z}^{\prime}, \mid \varepsilon_{\psi}, \varepsilon_{z}\right)
$$

Rearranging the dividend term and dividing the numerator and denominator of the left hand side by $\psi$ gives

$$
\left.\tilde{V}(K, C, \psi, z)-\tilde{D}=\beta \frac{(V-\tilde{D}(1-\tau))}{(V-\tilde{D})+\frac{\tilde{E}}{\psi}+\frac{\nu(\tilde{E}, K)}{\psi}} \int V\left(K^{\prime}, C^{\prime}, \psi^{\prime}, z^{\prime}\right) d g\left(\varepsilon_{\psi}^{\prime}, \varepsilon_{z}^{\prime}, \mid \varepsilon_{\psi}, \varepsilon_{z}\right)\right) .
$$

Next, divide the above equation throughout by $\tilde{V}(K, C, \psi, z)-\tilde{D}$ and multiply by $\tilde{V}(K, C, \psi, z)-$ $\tilde{D}(1-\tau)+\tilde{E} / \psi+\nu(\tilde{E}, K) / \psi$ to obtain

$$
\tilde{V}(K, C, \psi, z)-\tilde{D}+\frac{\tilde{E}}{\psi}+\frac{\nu(\tilde{E}, K)}{\psi}=\beta \int V\left(K^{\prime}, C^{\prime}, \psi^{\prime}, z^{\prime}\right) d g\left(\varepsilon_{\psi}^{\prime}, \varepsilon_{z}^{\prime}, \mid \varepsilon_{\psi}, \varepsilon_{z}\right)
$$

Thus $\tilde{V}, \tilde{D}$, and $\tilde{E}$ also solve equation (12).

Conversely, let $\hat{V}$ be a solution to equation (12), with corresponding policy functions $\hat{D}$ and $\hat{E}$. One can use a similar approach to the above to show that $\hat{V}, \hat{D}$, and $\hat{E}$ also solve (11).

\section{Derivation of $\mu_{\psi}$}

Define the following matrices:

$$
Y=\left[\begin{array}{c}
\ln z \\
\ln \psi
\end{array}\right], C=\left[\begin{array}{c}
\mu_{z} \\
\mu_{\psi}
\end{array}\right], R=\left[\begin{array}{cc}
\rho_{z} & 0 \\
\rho_{z \psi} & \rho_{\psi}
\end{array}\right], \epsilon=\left[\begin{array}{c}
\epsilon_{z} \\
\epsilon_{\psi}
\end{array}\right] \Sigma=\left[\begin{array}{cc}
\sigma_{z}^{2} & 0 \\
0 & \sigma_{\psi}^{2}
\end{array}\right]
$$


Then, the joint transition equation can be written as the following $\operatorname{VAR}(1)$ :

$$
Y_{t+1}=C+R Y_{t}+\epsilon, \quad \epsilon \sim N(0, \Sigma)
$$

The unconditional mean of $Y$ is given by the following expression:

$$
E[Y]=\left(I_{2}-R\right)^{-1} C,
$$

where $I_{n}$ denotes a identity matrix of order $n$. The unconditional variance of $Y$ is given by:

$$
\operatorname{Vec}(\operatorname{Var}(Y))=\left[\left(I_{4}-(R \otimes R)\right]^{-1} \operatorname{Vec}(\Sigma)\right.
$$

where Vec denotes the vectorization operator and $\otimes$ denotes the Kronecker product. For notational

convenience, let $M=\left[\left(I_{4}-(R \otimes R)\right]^{-1}\right.$. One can then derive the unconditional mean and variance of $Y(2)=\ln \psi$ as:

$$
\begin{aligned}
E[\ln \psi] & =\frac{1}{\left(1-\rho_{z}\right)\left(1-\rho_{\psi}\right)}\left(\rho_{z \psi} \mu_{z}+\left(1-\rho_{z}\right) \mu_{\psi}\right) \\
\operatorname{Var}(\ln \psi) & =M(4,1) \sigma_{z}^{2}+\frac{\sigma_{\psi}^{2}}{\left(1-\rho_{\psi}^{2}\right)}
\end{aligned}
$$

where $M(4,1)$ denotes the $(4,1)^{\text {th }}$ element of the matrix $M$. The restriction that the unconditional expectation of the misvaluation term equals one implies that

$$
\ln E[\psi]=0, \quad \Rightarrow \quad E[\ln \psi]+0.5 \operatorname{Var}(\ln \psi)=0
$$

Some algebra then reveals that

$$
\mu_{\psi}=-\left[\frac{1}{2}\left(1-\rho_{\psi}\right) M(4,1) \sigma_{z}^{2}+\frac{\sigma_{\psi}^{2}}{2\left(1+\rho_{\psi}\right)}+\frac{\rho_{z \psi} \mu_{z}}{1-\rho_{z}}\right]
$$

\section{Time-Varying Expected Returns}

Let $x_{t}$ be an aggregate productivity variable that takes one of two values, $x_{l}, x_{h}$. Let $x_{l}$ denote a recessionary state and $x_{h}$ an expansionary state $\left(x_{h}>x_{l}\right)$. The probability of remaining in a recessionary state is given by $p_{l}$, and the probability of remaining in an expansionary state is given by $p_{h}$. This implies expected durations of recessions and expansions of $1 /\left(1-p_{l}\right)$ and $1 /\left(1-p_{h}\right)$, respectively. In addition, we impose the restriction that the unconditional expectation 
of the aggregate productivity shocks equals 1 so that average profits remains unchanged from the previous model..$^{5}$

The expected return varies with aggregate productivity $x_{t}$. Denote the conditional expected return as

$$
\beta m\left(x, x^{\prime}\right)
$$

Following the production-based asset pricing literature, the time-varying expected return can be parameterized as a function of current and future aggregate productivity. Thus,

$$
\log m\left(x, x^{\prime}\right)=m_{0}+m_{1}\left(x^{\prime}-x\right)
$$

Economic reasoning suggests that investors place a higher valuation on assets that payoff in bad states of the world. This imposes the requirement that $m_{1}<0$. In order to ensure that average discount rates remain unchanged from the model without aggregate shocks, we require that $E\left[m\left(x, x^{\prime}\right)\right]=1 .^{6}$

Given these assumptions, the expanded model can be written as follows:

$$
\begin{aligned}
v(c, \psi, z, x)= & \max _{c^{\prime}, d, e, i} d-\frac{e}{\psi}-\frac{\nu_{i} e^{2} \mathcal{I}(e>0)}{2 \psi}-\frac{\nu_{r} e^{2} \mathcal{I}(e \leq 0)}{2 \psi} \\
& +\beta E\left[m\left(x, x^{\prime}\right) v\left(c^{\prime}, \psi^{\prime}, z^{\prime}, x^{\prime}\right)\right](1-\delta+i) . \\
d-e+\mathcal{I}(e>0) a_{1} e= & z x\left(1-\tau_{c}\right)-i-\frac{\lambda i^{2}}{2}+c\left(1+r-r \tau_{c}\right)-c^{\prime}(1-\delta+i)+\delta \tau_{c}, \\
-c^{\prime} \leq & \phi, \quad d \geq 0 .
\end{aligned}
$$

The solution to the expanded problem takes into account that the static allocation decisions now depend on the aggregate productivity state. It also takes into account the impact of the pricing kernel $m\left(x, x^{\prime}\right)$ and the transition matrix for $x$ on the expected future value of the firm.

We calibrate $p_{l}$ and $p_{h}$ to match average durations of recessions and expansions of 16 and 42 months, respectively. ${ }^{7}$ We calibrate $x_{l}$ and $x_{h}$ to generate an average decline in output from its

\footnotetext{
${ }^{5}$ Formally, this imposes the restriction that $x_{h} \frac{1-p_{l}}{2-p_{h}-p_{l}}+x_{l} \frac{1-p_{h}}{2-p_{h}-p_{l}}=1$.

${ }^{6}$ This yields the following equation: $\exp \left(m_{0}\right)\left[\frac{1-p_{h}}{2-p_{h}-p_{l}}\left(p_{l}+\left(1-p_{l}\right) \exp \left(m_{1}\left(x_{h}-x_{l}\right)\right)\right)+\frac{1-p_{l}}{2-p_{h}-p_{l}}\left(p_{h}+\left(1-p_{h}\right) \exp \left(m_{1}\left(x_{l}-x_{h}\right)\right)\right)\right]=1$

${ }^{7}$ See http://www.nber.org/cycles.html for information on duration of recessions.
} 
trend growth path of 4 percent, similar to the output declines observed in U.S. post-war recessions. Combined with the restriction that $E[x]=1$, one obtains $x_{h}=1.011$ and $x_{l}=0.971$.

\section{Estimation}

We now give a brief outline of the estimation procedure, which draws from Ingram and Lee (1991) Duffie and Singleton (1993), but which is adapted to our panel setting. Suppose we have $J$ variables contained in the data vector $x_{i t}, i=1, \ldots, n ; t=1, \ldots, T$. We assume that the $J \times T$ matrix $x_{i}$ is i.i.d., but we allow for possible dependence among the elements of $x_{i}$. Let $y_{i t k}(b)$ be a data vector from simulation $k, i=1, \ldots, n, t=1, \ldots, T$, and $k=1, \ldots, K$. Here, $K$ is the number of times the model is simulated. (In practice, $K$ is the simulated sample size, 150,000, divided by the actual sample size).

The simulated data, $y_{i t k}(b)$, depend on a vector of structural parameters, $b$. In our application $b \equiv\left(\alpha_{1}, \lambda, \delta, \rho_{\psi}, \sigma_{\psi}, \mu, \rho_{z}, \sigma_{z}, \nu_{i}, \nu_{r}, \rho_{z \psi}\right)$. The goal is to estimate $b$ by matching a set of simulated moments, denoted as $h\left(y_{i t k}(b)\right)$, with the corresponding set of actual data moments, denoted as $h\left(x_{i t}\right)$. Our moments are listed in the text, and we denote the number of moments as $H$. Define the sample moment vector

$$
g\left(x_{i t}, b\right)=(n T)^{-1} \sum_{i=1}^{n} \sum_{t=1}^{T}\left[h\left(x_{i t}\right)-K^{-1} \sum_{k=1}^{K} h\left(y_{i t k}(b)\right)\right] .
$$

The simulated moments estimator of $b$ is then defined as the solution to the minimization of

$$
\hat{b}=\arg \min _{b} g(x, b)^{\prime} \hat{W} g(x, b),
$$

in which $\hat{W}$ is a positive definite matrix that converges in probability to a deterministic positive definite matrix $W$.

Our weight matrix, $\hat{W}$, differs from that given in Ingram and Lee (1991). First, we calculate it using the influence function approach in Erickson and Whited (2002). Second, it is not the optimal weight matrix, and we justify this choice as follows. First, because our model is of an individual firm, we want the influence functions to reflect within-firm variation. Because our data contain a great deal of heterogeneity, we therefore demean each of our variables at the firm level and then calculate the influence functions for each moment using the demeaned data. We then covary the 
influence functions (summing over both $i$ and $t$ ) to obtain an estimate of the covariance matrix of the moments. The estimated weight matrix, $\hat{W}$, is the inverse of this covariance matrix. Note that the weight matrix does not depend on the parameter vector, $b$.

Two details regarding this issue are important. First, neither the influence functions for the autocorrelation coefficients nor the coefficients themselves are calculated using demeaned data because we obtain them using the double-differencing estimator in Han and Phillips (2010). Thus, we remove heterogeneity by differencing rather than by demeaning. Second, although we cannot use firm-demeaned data to calculate the means in the moment vector, we do use demeaned data to calculate the influence functions for these moments. Otherwise, the influence functions for the means would reflect primarily cross sectional variation, whereas the influence functions for the rest of the moments would reflect within-firm variation. In this case, the estimation would put the least weight on the mean moments, which does not appear to be a sensible economic objective.

The above described weight matrix does achieve our goal of reflecting within-firm variation. However, it does not account for any temporal dependence in the data. We therefore calculate our standard errors using the optimal weight matrix, which is the inverse of a clustered moment covariance matrix. We calculate the estimate of this covariance matrix, denoted $\hat{\Omega}$, as follows. Let $\phi_{i t}$ be the influence function of the moment vector $g\left(x_{i t}, b\right)$ for firm $i$ at time $t . \phi_{i t}$ then has dimension $H$. Note that this influence function is of the actual moment vector $g\left(x_{i t}, b\right)$, which implies that we do not use demeaned data to calculate the influence functions for the means or autocorrelation coefficients, but that we do use demeaned data to calculate the rest of the moments. The estimate of $\Omega$ is

$$
\frac{1}{n T} \sum_{i=1}^{n}\left(\sum_{t=1}^{T} \phi_{i t}\right)\left(\sum_{t=1}^{T} \phi_{i t}\right)^{\prime}
$$

Note that this estimate does not depend on $b$. Note also that if we were to use demeaned data, the elements corresponding to the mean moments would be zero.

The standard errors are then given by the usual GMM formula, adjusted for simulation error. Letting $G \equiv \partial g\left(x_{i t}, b\right) / \partial b$, the asymptotic distribution of $b$ is

$$
\operatorname{avar}(\hat{b}) \equiv\left(1+\frac{1}{K}\right)\left[G W G^{\prime}\right]^{-1}\left[G W \Omega W G^{\prime}\right]\left[G W G^{\prime}\right]^{-1}
$$


Calculations are based on a sample of nonfinancial firms from the annual 2011 COMPUSTAT industrial files. The sample period is from 1987 to 2010. The sample is split into four groups: large and small firms in the first part of the sample (through 2003), and large and small firms in the second part of the sample. The estimation is done with SMM, which chooses structural model parameters by matching the moments from a simulated panel of firms to the corresponding moments from the data. Panel A reports the simulated and actual moments and the clustered t-statistics for the differences between the corresponding moments. Panel B reports the estimated structural parameters, with clustered standard errors in parentheses. $a_{1}$ is the linear equity issuance cost, $\lambda$ is the cost of adjusting the capital stock, and $\delta$ is the rate of capital depreciation. $\mu$ is the drift of the profitability process, $\rho_{z}$ is its serial correlation, and $\sigma_{z}$ is the standard deviation of the innovation to this process. $\rho_{\psi}$ and $\sigma_{\psi}$ are the serial correlation of the misvaluation process and the standard deviation of its innovation. $\rho_{z \psi}$ governs the serial correlation of the two processes. $\nu_{i}$ and $\nu_{r}$ are penalties on equity issuance and repurchases.

A. Moments

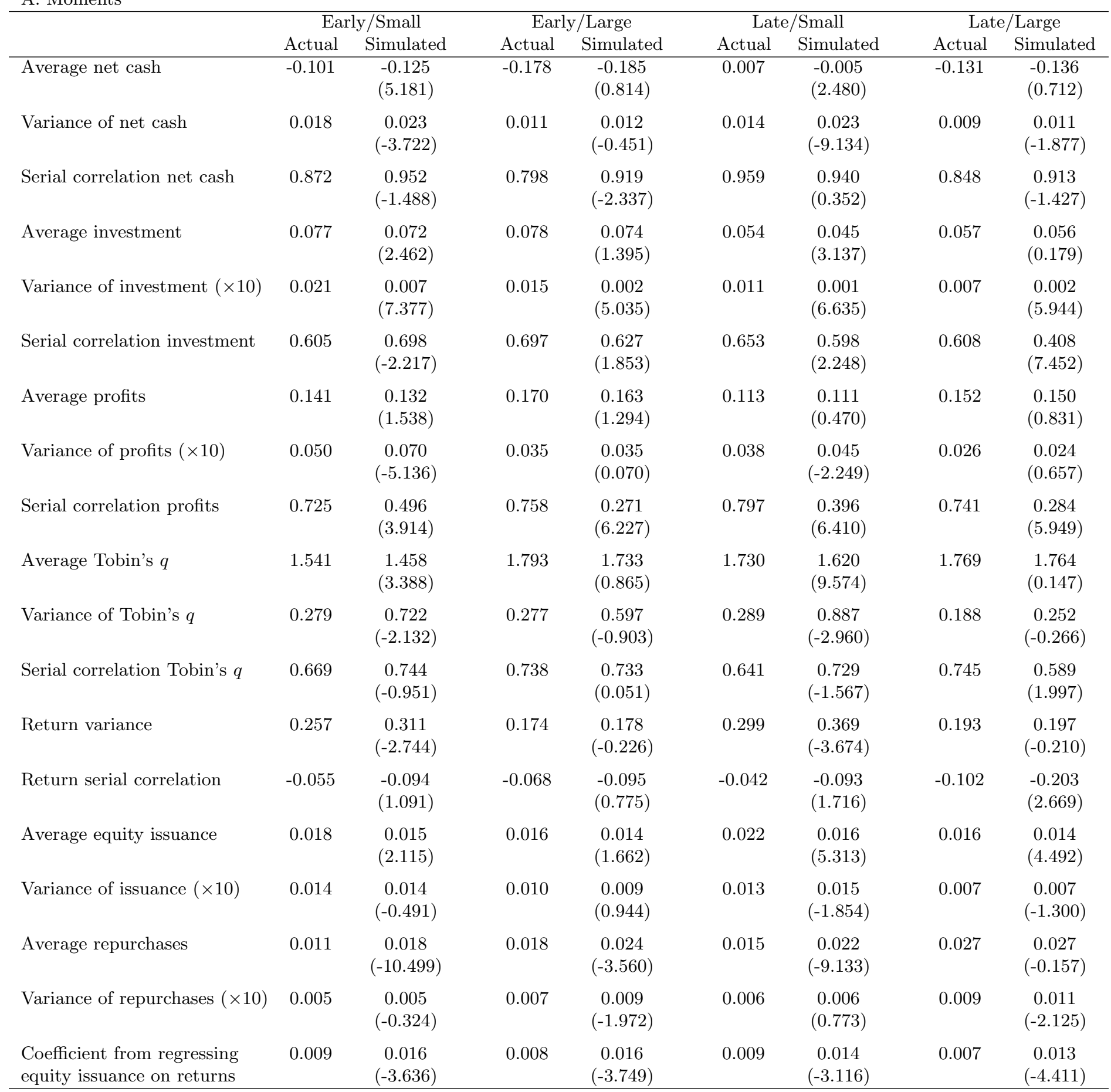


B. Parameter estimates

\begin{tabular}{|c|c|c|c|c|c|c|c|c|c|c|c|}
\hline & $a_{1}$ & $\lambda$ & $\delta$ & $\rho_{\psi}$ & $\sigma_{\psi}$ & $\mu$ & $\rho_{z}$ & $\sigma_{z}$ & $\nu_{i}$ & $\nu_{r}$ & $\rho_{z \psi}$ \\
\hline \multicolumn{12}{|l|}{ Early Small } \\
\hline & $\begin{array}{c}0.198 \\
(0.086)\end{array}$ & $\begin{array}{c}6.110 \\
(0.366)\end{array}$ & $\begin{array}{c}0.066 \\
(0.001)\end{array}$ & $\begin{array}{c}0.462 \\
(0.048)\end{array}$ & $\begin{array}{c}0.371 \\
(0.022)\end{array}$ & $\begin{array}{c}-1.026 \\
(0.029)\end{array}$ & $\begin{array}{c}0.530 \\
(0.015)\end{array}$ & $\begin{array}{c}0.485 \\
(0.015)\end{array}$ & $\begin{array}{c}8.761 \\
(3.194)\end{array}$ & $\begin{array}{c}8.934 \\
(0.750)\end{array}$ & $\begin{array}{c}0.464 \\
(0.039)\end{array}$ \\
\hline \multicolumn{12}{|l|}{ Early Large } \\
\hline & $\begin{array}{c}0.002 \\
(0.095)\end{array}$ & $\begin{array}{l}11.220 \\
(0.450)\end{array}$ & $\begin{array}{c}0.069 \\
(0.001)\end{array}$ & $\begin{array}{c}0.688 \\
(0.040)\end{array}$ & $\begin{array}{c}0.354 \\
(0.011)\end{array}$ & $\begin{array}{c}-1.354 \\
(0.011)\end{array}$ & $\begin{array}{c}0.275 \\
(0.008)\end{array}$ & $\begin{array}{c}0.335 \\
(0.015)\end{array}$ & $\begin{array}{l}14.897 \\
(2.900)\end{array}$ & $\begin{array}{c}6.633 \\
(0.268)\end{array}$ & $\begin{array}{c}0.388 \\
(0.073)\end{array}$ \\
\hline Late small & $\begin{array}{c}0.000 \\
(0.089)\end{array}$ & $\begin{array}{l}14.595 \\
(0.862)\end{array}$ & $\begin{array}{c}0.068 \\
(0.002)\end{array}$ & $\begin{array}{c}0.626 \\
(0.040)\end{array}$ & $\begin{array}{c}0.451 \\
(0.014)\end{array}$ & $\begin{array}{l}-1.354 \\
(0.042)\end{array}$ & $\begin{array}{c}0.422 \\
(0.022)\end{array}$ & $\begin{array}{c}0.499 \\
(0.016)\end{array}$ & $\begin{array}{l}16.170 \\
(2.999)\end{array}$ & $\begin{array}{c}10.866 \\
(0.548)\end{array}$ & $\begin{array}{c}0.386 \\
(0.017)\end{array}$ \\
\hline & $\begin{array}{c}0.000 \\
(0.103)\end{array}$ & $\begin{array}{l}15.035 \\
(0.925)\end{array}$ & $\begin{array}{c}0.076 \\
(0.002)\end{array}$ & $\begin{array}{c}0.501 \\
(0.045)\end{array}$ & $\begin{array}{c}0.355 \\
(0.007)\end{array}$ & $\begin{array}{c}-1.384 \\
(0.028)\end{array}$ & $\begin{array}{c}0.287 \\
(0.011)\end{array}$ & $\begin{array}{c}0.301 \\
(0.012)\end{array}$ & $\begin{array}{l}11.959 \\
(2.219)\end{array}$ & $\begin{array}{c}5.451 \\
(0.277)\end{array}$ & $\begin{array}{c}0.316 \\
(0.057)\end{array}$ \\
\hline
\end{tabular}


Table 3: Simulated Moments Estimation; Pricing Kernel Model

Calculations are based on a sample of nonfinancial firms from the annual 2011 COMPUSTAT industrial files. The sample period is from 1987 to 2010. The sample is split into four groups: large and small firms in the first part of the sample (through 2003), and large and small firms in the second part of the sample. The estimation is done with SMM, which chooses structural model parameters by matching the moments from a simulated panel of firms to the corresponding moments from the data. Panel A reports the simulated and actual moments and the clustered t-statistics for the differences between the corresponding moments. Panel B reports the estimated structural parameters, with clustered standard errors in parentheses. $a_{1}$ is the linear equity issuance cost, $\lambda$ is the cost of adjusting the capital stock, and $\delta$ is the rate of capital depreciation. $\mu$ is the drift of the profitability process, $\rho_{z}$ is its serial correlation, and $\sigma_{z}$ is the standard deviation of the innovation to this process. $\rho_{\psi}$ and $\sigma_{\psi}$ are the serial correlation of the misvaluation process and the standard deviation of its innovation. $\rho_{z \psi}$ governs the serial correlation of the two processes. $\nu_{i}$ and $\nu_{r}$ are penalties on equity issuance and repurchases.

A. Moments

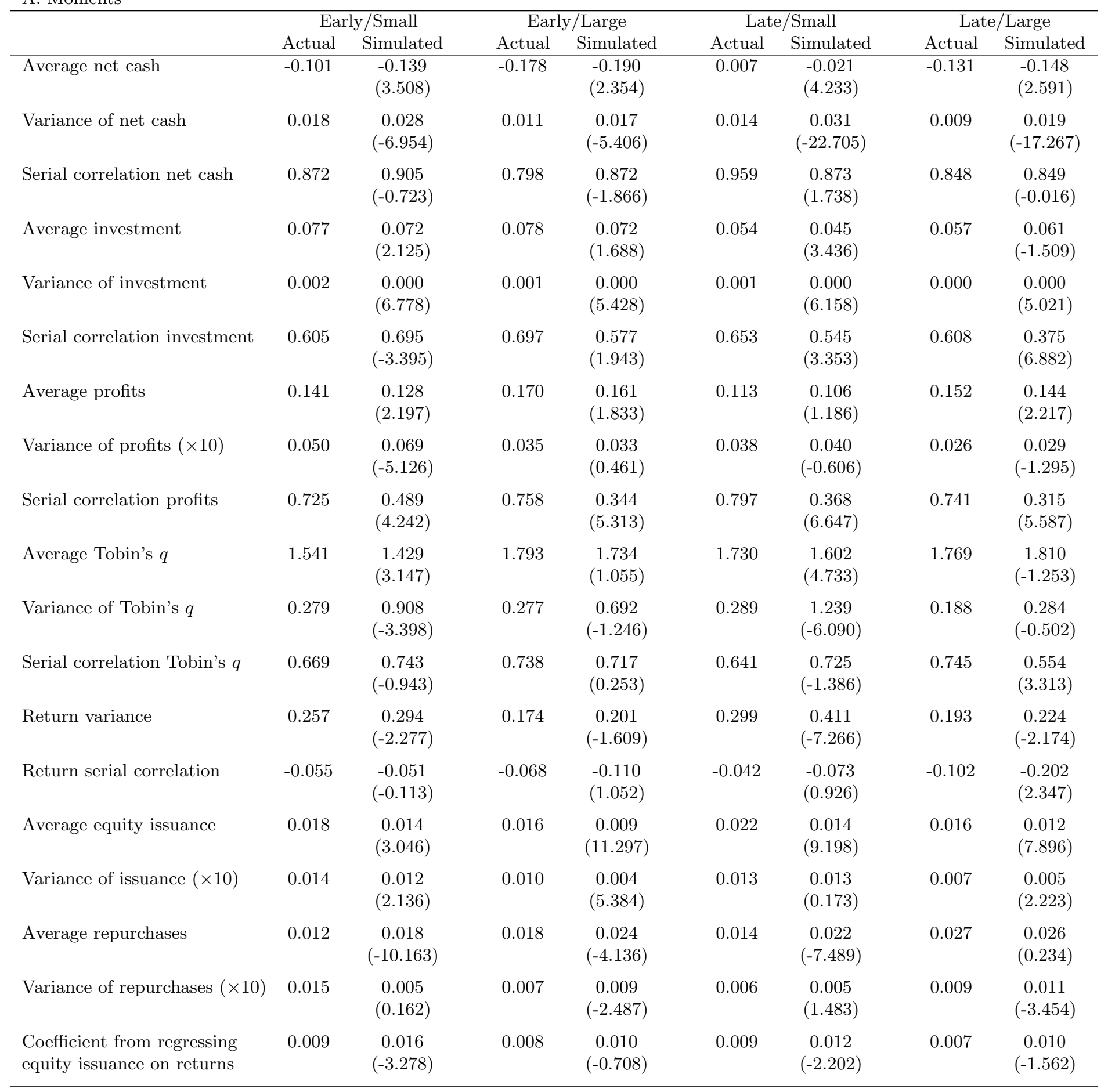


B. Parameter estimates

\begin{tabular}{|c|c|c|c|c|c|c|c|c|c|c|c|}
\hline & $a_{1}$ & $\lambda$ & $\delta$ & $\rho_{\psi}$ & $\sigma_{\psi}$ & $\mu$ & $\rho_{z}$ & $\sigma_{z}$ & $\nu_{i}$ & $\nu_{r}$ & $\rho_{z \psi}$ \\
\hline \multicolumn{12}{|l|}{ Early Small } \\
\hline & $\begin{array}{c}0.195 \\
(0.033)\end{array}$ & $\begin{array}{c}5.141 \\
(0.652)\end{array}$ & $\begin{array}{c}0.067 \\
(0.001)\end{array}$ & $\begin{array}{c}0.530 \\
(0.085)\end{array}$ & $\begin{array}{c}0.362 \\
(0.021)\end{array}$ & $\begin{array}{l}-1.050 \\
(0.052)\end{array}$ & $\begin{array}{c}0.527 \\
(0.026)\end{array}$ & $\begin{array}{c}0.499 \\
(0.012)\end{array}$ & $\begin{array}{c}10.508 \\
(1.694)\end{array}$ & $\begin{array}{c}9.179 \\
(1.190)\end{array}$ & $\begin{array}{c}0.443 \\
(0.126)\end{array}$ \\
\hline \multicolumn{12}{|l|}{ Early Large } \\
\hline & $\begin{array}{c}0.145 \\
(0.107)\end{array}$ & $\begin{array}{l}10.585 \\
(0.351)\end{array}$ & $\begin{array}{c}0.068 \\
(0.003)\end{array}$ & $\begin{array}{c}0.716 \\
(0.059)\end{array}$ & $\begin{array}{c}0.391 \\
(0.020)\end{array}$ & $\begin{array}{l}-1.217 \\
(0.027)\end{array}$ & $\begin{array}{c}0.354 \\
(0.010)\end{array}$ & $\begin{array}{c}0.323 \\
(0.012)\end{array}$ & $\begin{array}{l}18.789 \\
(6.493)\end{array}$ & $\begin{array}{c}6.743 \\
(0.698)\end{array}$ & $\begin{array}{c}0.191 \\
(0.157)\end{array}$ \\
\hline Late small & $\begin{array}{c}0.099 \\
(0.200)\end{array}$ & $\begin{array}{c}12.208 \\
(1.226)\end{array}$ & $\begin{array}{c}0.070 \\
(0.002)\end{array}$ & $\begin{array}{r}0.6944 \\
(0.038)\end{array}$ & $\begin{array}{c}0.485 \\
(0.019)\end{array}$ & $\begin{array}{l}-1.434 \\
(0.027)\end{array}$ & $\begin{array}{c}0.398 \\
(0.011)\end{array}$ & $\begin{array}{c}0.499 \\
(0.015)\end{array}$ & $\begin{array}{l}17.408 \\
(3.630)\end{array}$ & $\begin{array}{r}11.436 \\
(1.166)\end{array}$ & $\begin{array}{c}0.344 \\
(0.065)\end{array}$ \\
\hline & $\begin{array}{c}0.069 \\
(0.088)\end{array}$ & $\begin{array}{c}14.706 \\
(0.187)\end{array}$ & $\begin{array}{c}0.073 \\
(0.001)\end{array}$ & $\begin{array}{c}0.524 \\
(0.033)\end{array}$ & $\begin{array}{c}0.381 \\
(0.007)\end{array}$ & $\begin{array}{c}-1.344 \\
(0.018)\end{array}$ & $\begin{array}{c}0.326 \\
(0.015)\end{array}$ & $\begin{array}{c}0.338 \\
(0.009)\end{array}$ & $\begin{array}{l}13.235 \\
(2.146)\end{array}$ & $\begin{array}{c}5.131 \\
(0.230)\end{array}$ & $\begin{array}{c}0.001 \\
(1.265)\end{array}$ \\
\hline
\end{tabular}




\section{Table 4: Parameter Estimates for Industry Estimations}

Calculations are based on a sample of nonfinancial firms from the annual 2011 COMPUSTAT industrial files. The sample period is from 1987 to 2010. The sample is split into eight industry groups. SIC13 is oil and gas extraction; SIC20 is food products; SIC28 is chemicals and allied products; SIC35 is machinery and computer equipment; SIC26 is electronic and electrical equipment; SIC38 is measuring instruments; SIC50 is wholesale trade; and SIC73 is business services. The estimation is done with SMM, which chooses structural model parameters by matching the moments from a simulated panel of firms to the corresponding moments from the data. This table reports the estimated structural parameters, with clustered standard errors in parentheses. $a_{1}$ is the linear equity issuance cost, $\lambda$ is the cost of adjusting the capital stock, and $\delta$ is the rate of capital depreciation. $\mu$ is the drift of the profitability process, $\rho_{z}$ is its serial correlation, and $\sigma_{z}$ is the standard deviation of the innovation to this process. $\rho_{\psi}$ and $\sigma_{\psi}$ are the serial correlation of the misvaluation process and the standard deviation of its innovation. $\rho_{z \psi}$ governs the serial correlation of the two processes. $\nu_{i}$ and $\nu_{r}$ are penalties on equity issuance and repurchases. The estimation is done for eight separate two-digit industries. The last line of the table presents average R\&D for each industry.

\begin{tabular}{|c|c|c|c|c|c|c|c|c|}
\hline & SIC13 & SIC 20 & SIC 28 & SIC 35 & SIC 36 & SIC 38 & SIC 50 & SIC 73 \\
\hline$a_{1}$ & $\begin{array}{c}0.002 \\
(0.528)\end{array}$ & $\begin{array}{c}0.139 \\
(0.226)\end{array}$ & $\begin{array}{c}0.000 \\
(0.392)\end{array}$ & $\begin{array}{c}0.045 \\
(0.026)\end{array}$ & $\begin{array}{c}0.000 \\
(0.366)\end{array}$ & $\begin{array}{c}0.000 \\
(0.251)\end{array}$ & $\begin{array}{c}0.198 \\
(0.154)\end{array}$ & $\begin{array}{c}0.000 \\
(1.008)\end{array}$ \\
\hline$\lambda$ & $\begin{array}{c}14.428 \\
(105.886)\end{array}$ & $\begin{array}{l}13.877 \\
(5.198)\end{array}$ & $\begin{array}{l}23.321 \\
(4.189)\end{array}$ & $\begin{array}{l}13.904 \\
(1.359)\end{array}$ & $\begin{array}{l}11.020 \\
(3.491)\end{array}$ & $\begin{array}{l}19.567 \\
(1.500)\end{array}$ & $\begin{array}{c}13.186 \\
(10.734)\end{array}$ & $\begin{array}{l}22.858 \\
(3.303)\end{array}$ \\
\hline$\delta$ & $\begin{array}{c}0.068 \\
(0.066)\end{array}$ & $\begin{array}{c}0.065 \\
(0.005)\end{array}$ & $\begin{array}{c}0.043 \\
(0.005)\end{array}$ & $\begin{array}{c}0.055 \\
(0.005)\end{array}$ & $\begin{array}{c}0.055 \\
(0.007)\end{array}$ & $\begin{array}{c}0.054 \\
(0.004)\end{array}$ & $\begin{array}{c}0.047 \\
(0.008)\end{array}$ & $\begin{array}{c}0.054 \\
(0.004)\end{array}$ \\
\hline$\rho_{\psi}$ & $\begin{array}{c}0.622 \\
(0.136)\end{array}$ & $\begin{array}{c}0.684 \\
(0.198)\end{array}$ & $\begin{array}{c}0.442 \\
(0.087)\end{array}$ & $\begin{array}{c}0.447 \\
(0.134)\end{array}$ & $\begin{array}{c}0.620 \\
(0.056)\end{array}$ & $\begin{array}{c}0.665 \\
(0.077)\end{array}$ & $\begin{array}{c}0.458 \\
(0.619)\end{array}$ & $\begin{array}{c}0.571 \\
(0.080)\end{array}$ \\
\hline$\sigma_{\psi}$ & $\begin{array}{c}0.453 \\
(0.089)\end{array}$ & $\begin{array}{c}0.296 \\
(0.066)\end{array}$ & $\begin{array}{c}0.333 \\
(0.036)\end{array}$ & $\begin{array}{c}0.355 \\
(0.038)\end{array}$ & $\begin{array}{c}0.458 \\
(0.024)\end{array}$ & $\begin{array}{c}0.359 \\
(0.028)\end{array}$ & $\begin{array}{c}0.295 \\
(0.103)\end{array}$ & $\begin{array}{c}0.434 \\
(0.048)\end{array}$ \\
\hline$\mu$ & $\begin{array}{l}-1.357 \\
(0.136)\end{array}$ & $\begin{array}{l}-1.244 \\
(0.075)\end{array}$ & $\begin{array}{l}-0.848 \\
(0.160)\end{array}$ & $\begin{array}{l}-0.894 \\
(0.079)\end{array}$ & $\begin{array}{l}-0.605 \\
(0.074)\end{array}$ & $\begin{array}{l}-1.416 \\
(0.103)\end{array}$ & $\begin{array}{l}-0.920 \\
(0.254)\end{array}$ & $\begin{array}{l}-0.889 \\
(0.053)\end{array}$ \\
\hline$\rho_{z}$ & $\begin{array}{c}0.422 \\
(0.009)\end{array}$ & $\begin{array}{c}0.345 \\
(0.036)\end{array}$ & $\begin{array}{c}0.604 \\
(0.069)\end{array}$ & $\begin{array}{c}0.611 \\
(0.025)\end{array}$ & $\begin{array}{c}0.757 \\
(0.030)\end{array}$ & $\begin{array}{c}0.336 \\
(0.045)\end{array}$ & $\begin{array}{c}0.611 \\
(0.085)\end{array}$ & $\begin{array}{c}0.583 \\
(0.029)\end{array}$ \\
\hline$\sigma_{z}$ & $\begin{array}{c}0.498 \\
(0.108)\end{array}$ & $\begin{array}{c}0.316 \\
(0.065)\end{array}$ & $\begin{array}{c}0.381 \\
(0.051)\end{array}$ & $\begin{array}{c}0.480 \\
(0.043)\end{array}$ & $\begin{array}{c}0.460 \\
(0.028)\end{array}$ & $\begin{array}{c}0.443 \\
(0.043)\end{array}$ & $\begin{array}{c}0.385 \\
(0.099)\end{array}$ & $\begin{array}{c}0.451 \\
(0.022)\end{array}$ \\
\hline$\nu_{i}$ & $\begin{array}{c}16.017 \\
(18.985)\end{array}$ & $\begin{array}{l}12.661 \\
(8.798)\end{array}$ & $\begin{array}{c}9.723 \\
(4.694)\end{array}$ & $\begin{array}{l}13.210 \\
(2.174)\end{array}$ & $\begin{array}{l}14.263 \\
(6.801)\end{array}$ & $\begin{array}{l}14.832 \\
(6.169)\end{array}$ & $\begin{array}{c}12.625 \\
(17.367)\end{array}$ & $\begin{array}{c}15.711 \\
(18.843)\end{array}$ \\
\hline$\nu_{r}$ & $\begin{array}{l}11.154 \\
(3.216)\end{array}$ & $\begin{array}{c}5.658 \\
(1.734)\end{array}$ & $\begin{array}{c}5.879 \\
(1.181)\end{array}$ & $\begin{array}{c}6.792 \\
(0.695)\end{array}$ & $\begin{array}{c}8.141 \\
(1.646)\end{array}$ & $\begin{array}{c}6.014 \\
(0.398)\end{array}$ & $\begin{array}{c}7.303 \\
(5.805)\end{array}$ & $\begin{array}{c}6.819 \\
(0.424)\end{array}$ \\
\hline$\rho_{z \psi}$ & $\begin{array}{c}0.404 \\
(0.124)\end{array}$ & $\begin{array}{c}0.362 \\
(0.142)\end{array}$ & $\begin{array}{c}0.460 \\
(0.180)\end{array}$ & $\begin{array}{c}0.442 \\
(0.089)\end{array}$ & $\begin{array}{c}0.189 \\
(0.044)\end{array}$ & $\begin{array}{c}0.415 \\
(0.046)\end{array}$ & $\begin{array}{c}0.491 \\
(0.543)\end{array}$ & $\begin{array}{c}0.404 \\
(0.123)\end{array}$ \\
\hline Average R\&D & 0.001 & 0.003 & 0.064 & 0.060 & 0.071 & 0.027 & 0.001 & 0.062 \\
\hline
\end{tabular}




\section{Table 5: Actual versus Model Implied Time-Series Correlations}

The figures preseted are the simple correlations between annual real ex-dividend equity returns and the indicated variables. Data calculations are based on a sample of nonfinancial firms from the annual 2011 COMPUSTAT industrial files. The sample period is from 1987 to 2010. "Saving," "Debt Issuance,", "Investment," "Dividends," "Equity Issuance," and "Repurchases" are all scaled by total book assets. Saving is the change in the stock of cash. Each variable is aggregated by taking the average across all firms in the sample in each year. The indicated correlations are then time-series correlations of these aggregated variables. Simulated calculations are based on data simulated from the model. The model parameterizations are from the estimates in Table 2.

\begin{tabular}{lcccccccc}
\hline & \multicolumn{2}{c}{ Early/Small } & \multicolumn{2}{c}{ Early/Large } & \multicolumn{2}{c}{ Late/Small } & \multicolumn{2}{c}{ Late/Large } \\
& Actual & Simulated & Actual & Simulated & Actual & Simulated & Actual & Simulated \\
\hline Investment & -0.286 & -0.171 & -0.124 & -0.096 & -0.605 & -0.015 & -0.607 & -0.059 \\
Net Saving & 0.524 & 0.424 & 0.121 & 0.207 & 0.914 & 0.218 & 0.651 & 0.305 \\
Equity Issuance & 0.383 & 0.329 & 0.028 & 0.313 & 0.116 & 0.310 & 0.033 & 0.423 \\
Repurchases & -0.400 & -0.367 & -0.081 & -0.363 & -0.801 & -0.366 & -0.407 & -0.439 \\
Dividends & -0.262 & 0.169 & -0.050 & 0.254 & -0.156 & 0.224 & 0.484 & 0.278 \\
\hline
\end{tabular}


Figure 1: Time Series Patterns: Small Firms
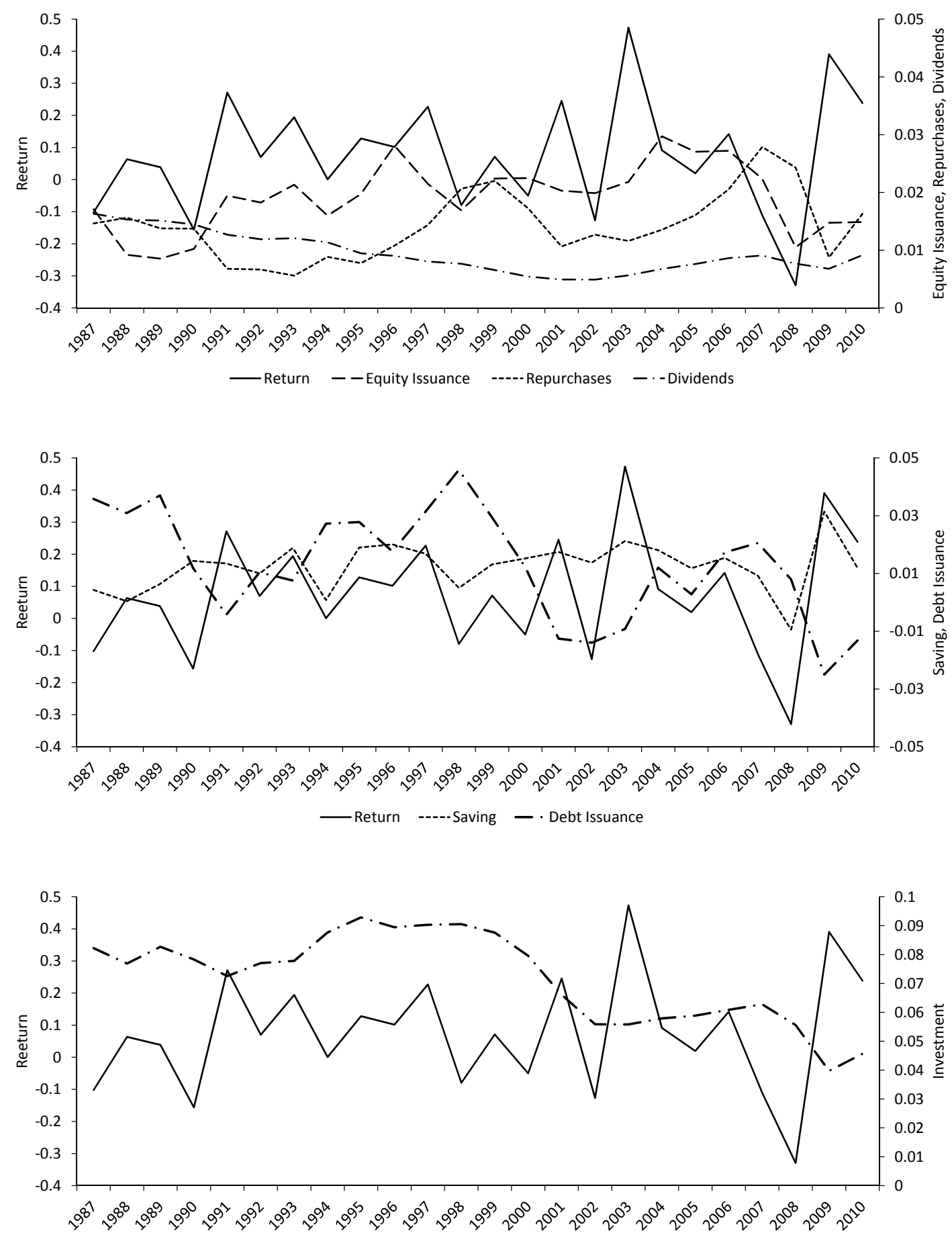

- Return - Investment

Calculations are based on a sample of nonfinancial firms from the annual 2011 COMPUSTAT industrial files. The sample period is from 1987 to 2010. Each series is the year-by-year asset-weighted average of a particular variable. Small firms are those whose assets are below the median for a particular year in the sample. "Investment", "Dividends," "Equity Issuance," "Saving," "Debt Issuance," and "Repurchases" are all scaled by total book assets. Saving is the change in the stock of cash. "Return" is the real annual ex-dividend equity return. 
Figure 2: Time Series Patterns: Large Firms
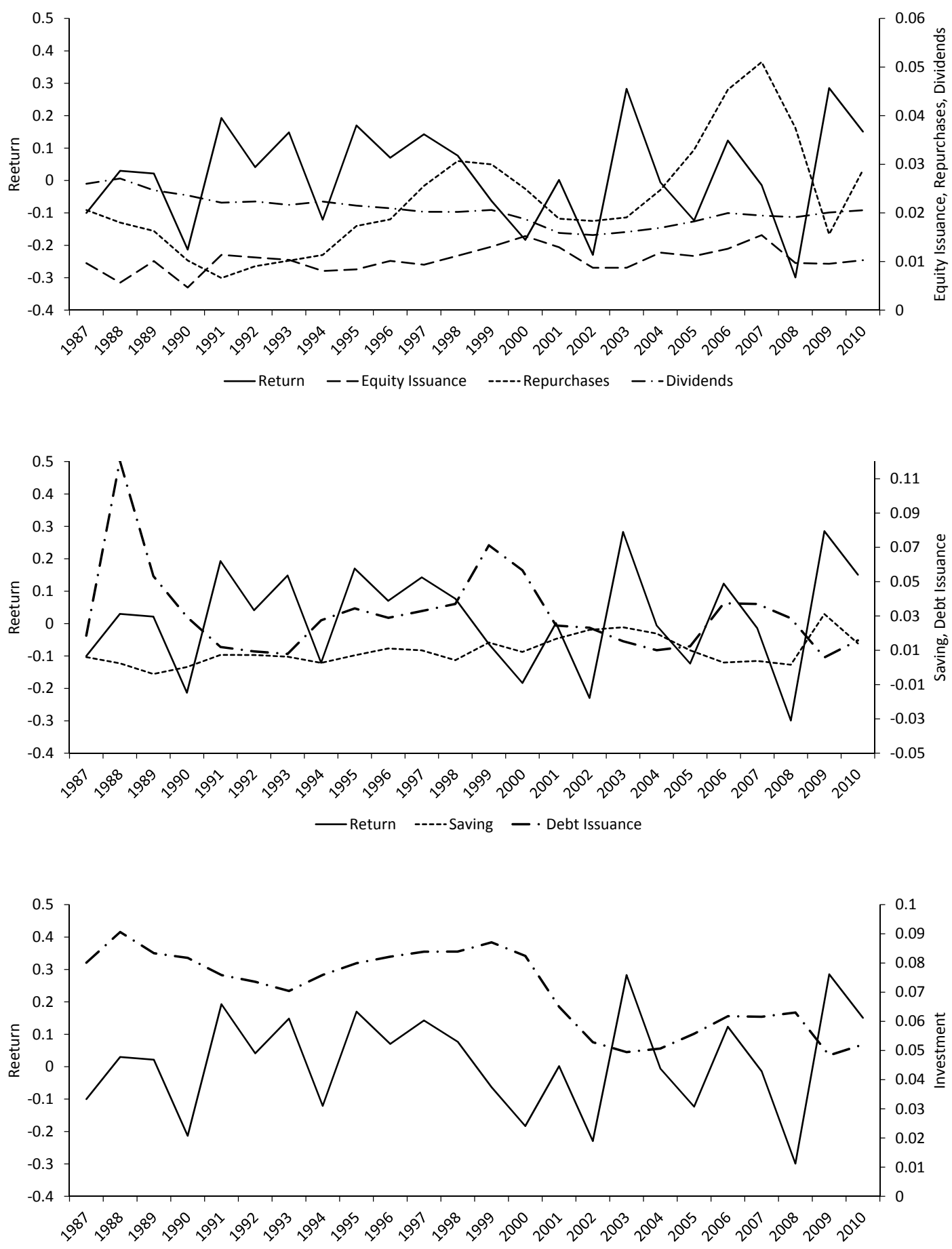

— Return - Investment

Calculations are based on a sample of nonfinancial firms from the annual 2011 COMPUSTAT industrial files. The sample period is from 1987 to 2010. Each series is the year-by-year asset-weighted average of a particular variable. Large firms are those whose assets are above the median for a particular year in the sample. "Investment", "Dividends," "Equity Issuance," "Saving," "Debt Issuance," and "Repurchases" are all scaled by total book assets. Saving is the change in the stock of cash. "Return" is the real annual ex-dividend equity return. 
Figure 3: Policy Functions
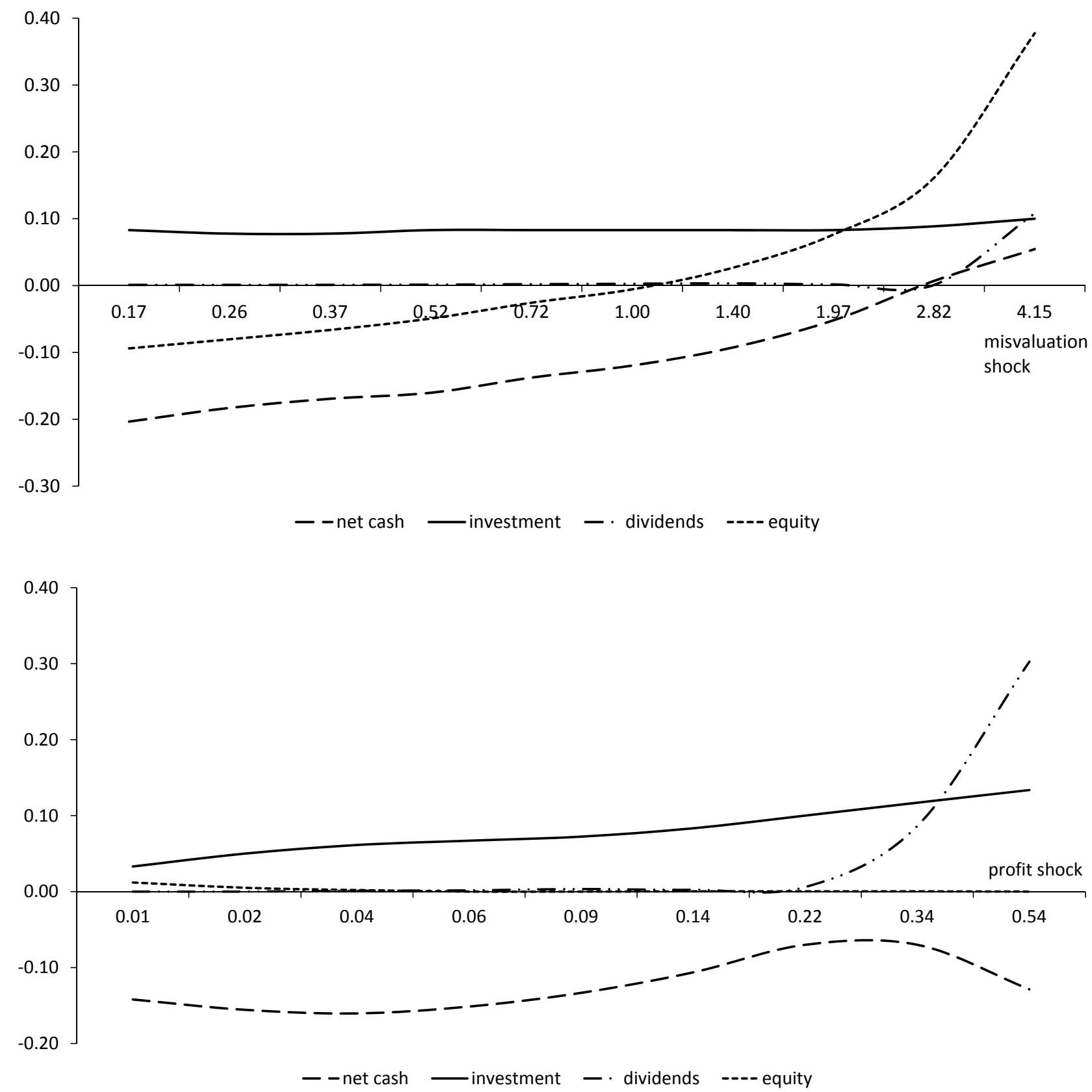

This figure depicts the optimal response of investment, equity transactions, cash, and dividends in response to the misvaluation shock, $\psi$ in the top panel, and to the productivity shock, $z$, in the bottom panel. Positive equity transactions are issuances, and negative equity transactions are repurchases. All variables are scaled by the capital stock, $K$. 
Figure 4: Matching Moments by Industry
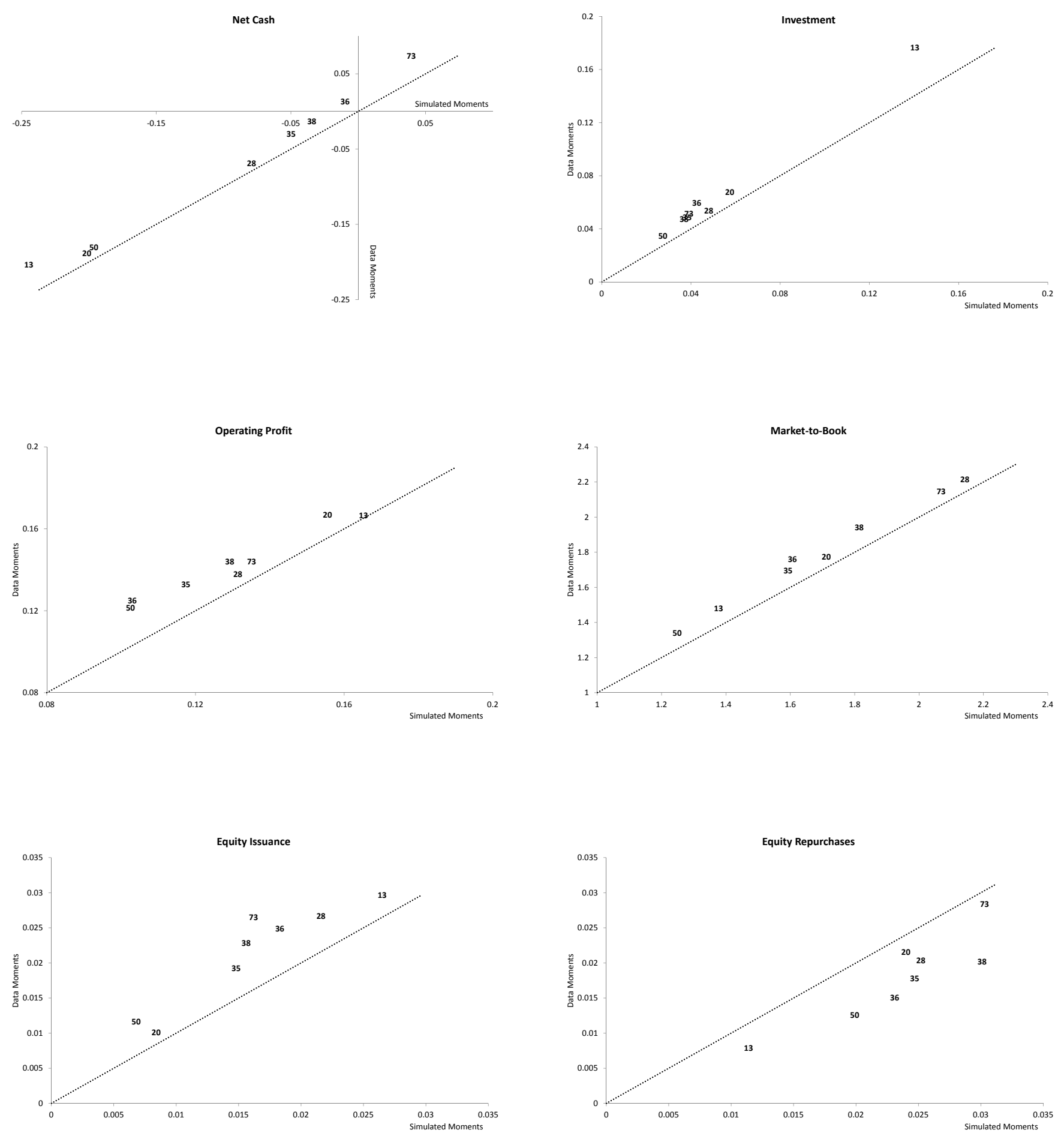

Calculations are based on a sample of nonfinancial firms from the annual 2011 COMPUSTAT industrial files. The sample period is from 1987 to 2010. The sample is split into eight industry groups. SIC13 is oil and gas extraction; SIC20 is food products; SIC28 is chemicals and allied products; SIC35 is machinery and computer equipment; SIC26 is electronic and electrical equipment; SIC38 is measuring instruments; SIC50 is wholesale trade; and SIC73 is business services. The estimation is done with SMM, which chooses structural model parameters by matching the moments from a simulated panel of firms to the corresponding moments from the data. This figure plots data moments versus simulated moments for the six "mean" moments. 
Figure 5: Counterfactuals
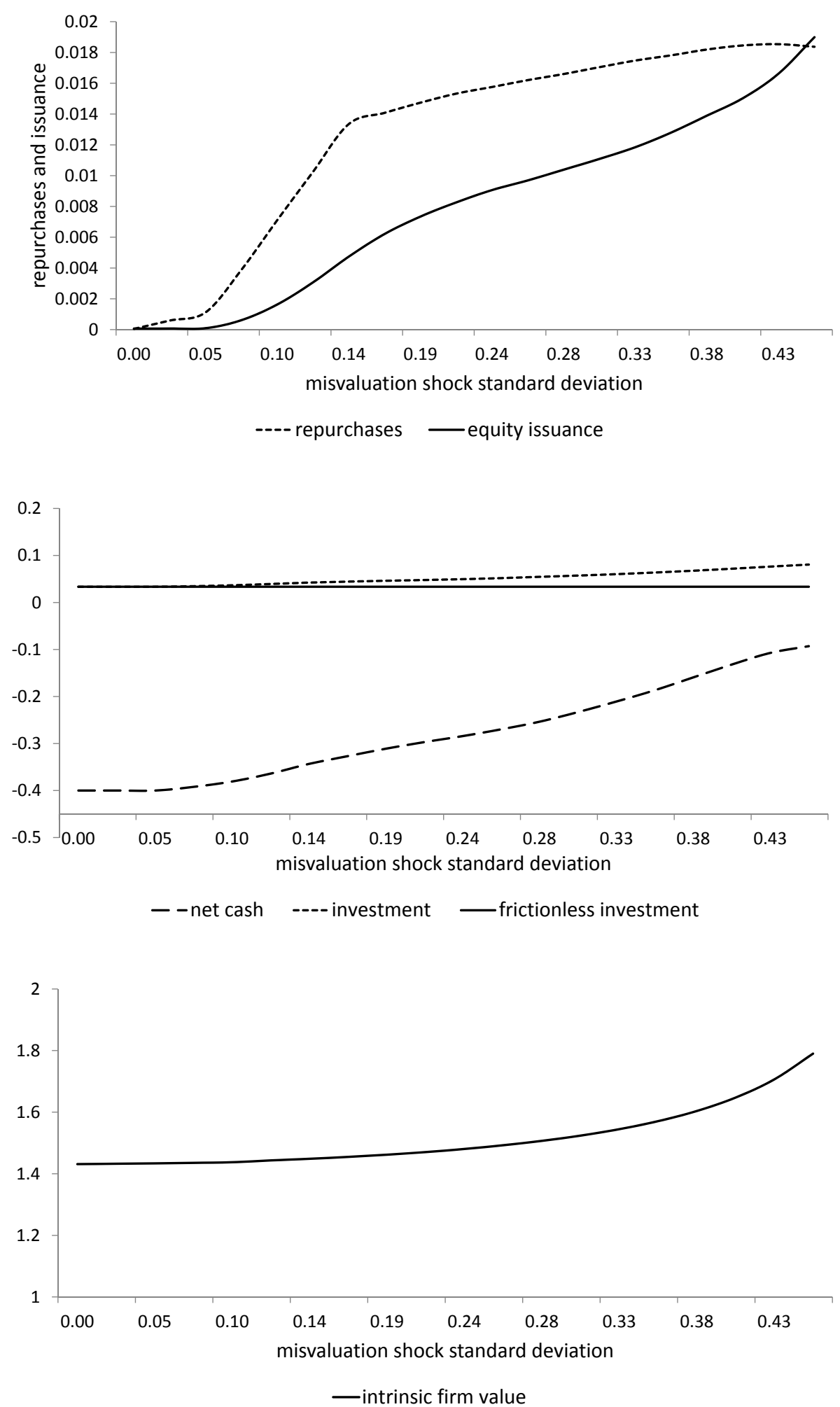

This figure is constructed as follows. We pick a grid for $\sigma_{\psi}$, the standard deviation of the innovation to the misvaluation shock. We then solve the model for each of the different parameter values, and then plot net cash, investment, equity issuance, equity repurchases, market value, and intrinsic value $\sigma_{\psi}$. The line labeled "Frictionless Investment" is the average rate of investment from a frictionless neoclassical $q$ model that is technologically identical to our model. 
Figure 6: Impulse Response Functions
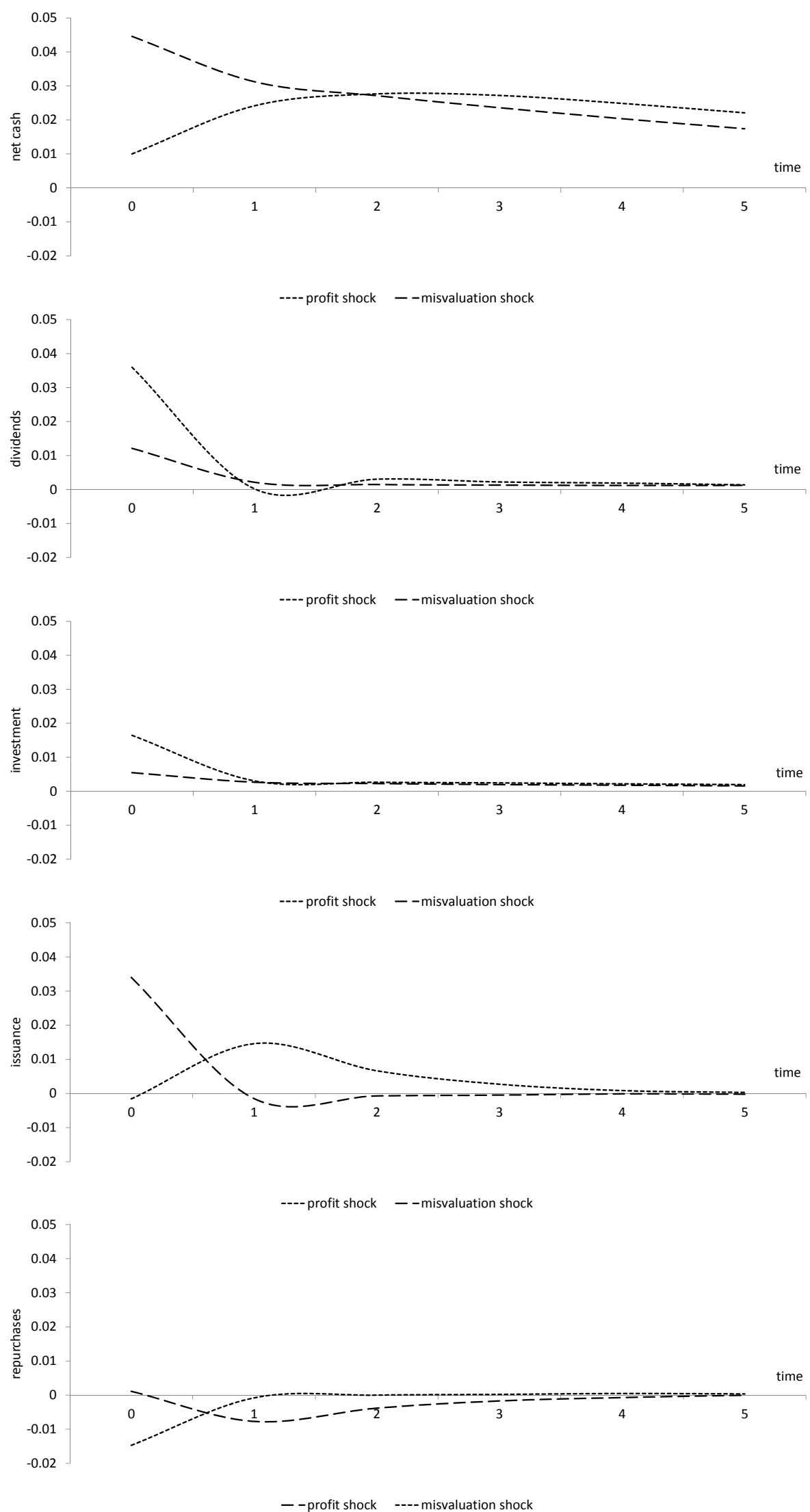

This figure depicts the responses of various variables to a one standard deviation innovation to each of the misvaluation and profit shock processes. 
Internet Appendix for "Equity Market Misvaluation, Financing, and Investment"

This Internet Appendix contains the results from two robustness checks mentioned in footnotes 1 and 3. Table A.1 presents the results from estimating the model using two more moments: the mean and variance of the ratio of dividends to assets. Table A.2 presents the results from estimating a version of the model that includes dividend taxation, in which the tax rate is set at 0.1 in the early period and 0.08 in the late period, and in which we use our baselines set of moments. 
Calculations are based on a sample of nonfinancial firms from the annual 2011 COMPUSTAT industrial files. The sample period is from 1987 to 2010. The sample is split into four groups: large and small firms in the first part of the sample (through 2003), and large and small firms in the second part of the sample. The estimation is done with SMM, which chooses structural model parameters by matching the moments from a simulated panel of firms to the corresponding moments from the data. Panel A reports the simulated and actual moments and the clustered t-statistics for the differences between the corresponding moments. Panel B reports the estimated structural parameters, with clustered standard errors in parentheses. $a_{1}$ is the linear equity issuance cost, $\lambda$ is the cost of adjusting the capital stock, and $\delta$ is the rate of capital depreciation. $\mu$ is the drift of the profitability process, $\rho_{z}$ is its serial correlation, and $\sigma_{z}$ is the standard deviation of the innovation to this process. $\rho_{\psi}$ and $\sigma_{\psi}$ are the serial correlation of the misvaluation process and the standard deviation of its innovation. $\rho_{z \psi}$ governs the serial correlation of the two processes. $\nu_{i}$ and $\nu_{r}$ are penalties on equity issuance and repurchases.

A. Moments

\begin{tabular}{|c|c|c|c|c|c|c|c|c|}
\hline & \multicolumn{2}{|c|}{ Early/Small } & \multicolumn{2}{|c|}{ Early/Large } & \multicolumn{2}{|c|}{ Late/Small } & \multicolumn{2}{|c|}{ Late/Large } \\
\hline & Actual & Simulated & Actual & Simulated & Actual & Simulated & Actual & Simulated \\
\hline Average net cash & -0.1011 & $\begin{array}{l}-0.1627 \\
(5.2626)\end{array}$ & -0.1780 & $\begin{array}{l}-0.2482 \\
(6.8048)\end{array}$ & 0.0066 & $\begin{array}{l}-0.0592 \\
(5.1171)\end{array}$ & -0.1310 & $\begin{array}{l}-0.1449 \\
(1.9780)\end{array}$ \\
\hline Variance of net cash & 0.0180 & $\begin{array}{c}0.0272 \\
(-5.5487)\end{array}$ & 0.0117 & $\begin{array}{c}0.0106 \\
(0.7729)\end{array}$ & 0.0143 & $\begin{array}{c}0.0305 \\
(-15.3678)\end{array}$ & 0.0095 & $\begin{array}{c}0.0171 \\
(-10.5529)\end{array}$ \\
\hline Serial correlation net cash & 0.8727 & $\begin{array}{c}0.9751 \\
(-1.7683)\end{array}$ & 0.7980 & $\begin{array}{c}0.9651 \\
(-2.4108)\end{array}$ & 0.9593 & $\begin{array}{c}0.9738 \\
(-0.2595)\end{array}$ & 0.8483 & $\begin{array}{c}0.9489 \\
(-1.6367)\end{array}$ \\
\hline Average investment & 0.0779 & $\begin{array}{c}0.0675 \\
(2.7414)\end{array}$ & 0.0789 & $\begin{array}{c}0.0559 \\
(5.2949)\end{array}$ & 0.0548 & $\begin{array}{c}0.0496 \\
(1.9448)\end{array}$ & 0.0570 & $\begin{array}{c}0.0595 \\
(-0.7485)\end{array}$ \\
\hline Variance of investment $(\times 10)$ & 0.0021 & $\begin{array}{c}0.0009 \\
(4.6214)\end{array}$ & 0.0015 & $\begin{array}{c}0.0001 \\
(5.4690)\end{array}$ & 0.0011 & $\begin{array}{c}0.0001 \\
(6.4396)\end{array}$ & 0.0007 & $\begin{array}{c}0.0001 \\
(5.0898)\end{array}$ \\
\hline Serial correlation investment & 0.6058 & $\begin{array}{c}0.7491 \\
(-4.1056)\end{array}$ & 0.6975 & $\begin{array}{c}0.6700 \\
(1.3174)\end{array}$ & 0.6535 & $\begin{array}{c}0.5142 \\
(2.4004)\end{array}$ & 0.6086 & $\begin{array}{c}0.5328 \\
(1.4381)\end{array}$ \\
\hline Average profits & 0.1413 & $\begin{array}{c}0.1165 \\
(3.8175)\end{array}$ & 0.1702 & $\begin{array}{c}0.1293 \\
(7.1023)\end{array}$ & 0.1137 & $\begin{array}{c}0.0934 \\
(3.3327)\end{array}$ & 0.1527 & $\begin{array}{c}0.1433 \\
(2.3635)\end{array}$ \\
\hline Variance of profits & 0.0050 & $\begin{array}{c}0.0035 \\
(2.9053)\end{array}$ & 0.0035 & $\begin{array}{c}0.0000 \\
(6.6743)\end{array}$ & 0.0038 & $\begin{array}{c}0.0019 \\
(5.2241)\end{array}$ & 0.0026 & $\begin{array}{c}0.0018 \\
(3.3652)\end{array}$ \\
\hline Serial correlation profits & 0.7252 & $\begin{array}{c}0.6298 \\
(1.6035)\end{array}$ & 0.7588 & $\begin{array}{c}0.3895 \\
(4.9550)\end{array}$ & 0.7972 & $\begin{array}{c}0.1999 \\
(9.2192)\end{array}$ & 0.7413 & $\begin{array}{c}0.2269 \\
(6.6402)\end{array}$ \\
\hline Average Tobin's $q$ & 1.5418 & $\begin{array}{c}1.4215 \\
(2.5651)\end{array}$ & 1.7933 & $\begin{array}{c}1.6925 \\
(1.9112)\end{array}$ & 1.7304 & $\begin{array}{c}1.7117 \\
(0.4299)\end{array}$ & 1.7690 & $\begin{array}{c}1.8135 \\
(-1.1630)\end{array}$ \\
\hline Variance of Tobin's $q$ & 0.2799 & $\begin{array}{c}0.5449 \\
(-1.2690)\end{array}$ & 0.2770 & $\begin{array}{c}0.1751 \\
(0.2800)\end{array}$ & 0.2899 & $\begin{array}{c}0.6308 \\
(-1.7640)\end{array}$ & 0.1882 & $\begin{array}{c}0.3034 \\
(-0.4925)\end{array}$ \\
\hline Serial correlation Tobin's $q$ & 0.6690 & $\begin{array}{c}0.7801 \\
(-1.4566)\end{array}$ & 0.7380 & $\begin{array}{c}0.8519 \\
(-1.2767)\end{array}$ & 0.6416 & $\begin{array}{c}0.6514 \\
(-0.1637)\end{array}$ & 0.7453 & $\begin{array}{c}0.5988 \\
(2.2399)\end{array}$ \\
\hline Return variance & 0.2571 & $\begin{array}{c}0.2303 \\
(1.2683)\end{array}$ & 0.1740 & $\begin{array}{c}0.0199 \\
(7.7026)\end{array}$ & 0.2991 & $\begin{array}{c}0.3446 \\
(-2.4198)\end{array}$ & 0.1935 & $\begin{array}{c}0.2085 \\
(-1.0693)\end{array}$ \\
\hline Return serial correlation & -0.0552 & $\begin{array}{l}-0.1524 \\
(2.4876)\end{array}$ & -0.0688 & $\begin{array}{c}-0.0374 \\
(-0.9683)\end{array}$ & -0.0426 & $\begin{array}{l}-0.1564 \\
(4.4332)\end{array}$ & -0.1027 & $\begin{array}{l}-0.1967 \\
(2.1609)\end{array}$ \\
\hline Average equity issuance & 0.0180 & $\begin{array}{c}0.0061 \\
(13.6850)\end{array}$ & 0.0160 & $\begin{array}{c}0.0015 \\
(9.7385)\end{array}$ & 0.0226 & $\begin{array}{c}0.0078 \\
(13.4499)\end{array}$ & 0.0163 & $\begin{array}{c}0.0038 \\
(24.2056)\end{array}$ \\
\hline Variance of issuance & 0.0014 & $\begin{array}{c}0.0001 \\
(8.1272)\end{array}$ & 0.0010 & $\begin{array}{c}0.0000 \\
(5.5411)\end{array}$ & 0.0013 & $\begin{array}{c}0.0003 \\
(8.9086)\end{array}$ & 0.0007 & $\begin{array}{c}0.0001 \\
(7.5958)\end{array}$ \\
\hline Average repurchases & 0.0118 & $\begin{array}{c}0.0192 \\
(-7.2735)\end{array}$ & 0.0183 & $\begin{array}{c}0.0232 \\
(-4.2277)\end{array}$ & 0.0146 & $\begin{array}{c}0.0170 \\
(-3.1030)\end{array}$ & 0.0274 & $\begin{array}{c}0.0293 \\
(-1.1459)\end{array}$ \\
\hline Variance of repurchases & 0.0005 & $\begin{array}{c}0.0007 \\
(-3.4720)\end{array}$ & 0.0007 & $\begin{array}{c}0.0011 \\
(-4.7385)\end{array}$ & 0.0006 & $\begin{array}{c}0.0004 \\
(3.8065)\end{array}$ & 0.0009 & $\begin{array}{c}0.0012 \\
(-4.0795)\end{array}$ \\
\hline Average dividends & 0.0083 & $\begin{array}{c}0.0021 \\
(11.0573)\end{array}$ & 0.0155 & $\begin{array}{c}0.0075 \\
(8.8381)\end{array}$ & 0.0077 & $\begin{array}{c}0.0056 \\
(6.2838)\end{array}$ & 0.0112 & $\begin{array}{c}0.0108 \\
(1.9564)\end{array}$ \\
\hline Variance of dividends & 0.0001 & $\begin{array}{c}0.0001 \\
(-1.1241)\end{array}$ & 0.0000 & $\begin{array}{c}0.0001 \\
(-12.9108)\end{array}$ & 0.0001 & $\begin{array}{c}0.0002 \\
(-13.4379)\end{array}$ & 0.0001 & $\begin{array}{c}0.0002 \\
(-24.8603)\end{array}$ \\
\hline $\begin{array}{l}\text { Coefficient from regressing } \\
\text { equity issuance on returns }\end{array}$ & 0.0093 & $\begin{array}{c}0.0061 \\
(1.4873)\end{array}$ & 0.0085 & $\begin{array}{c}0.0057 \\
(3.9103)\end{array}$ & 0.0090 & $\begin{array}{c}0.0068 \\
(1.1368)\end{array}$ & 0.0072 & $\begin{array}{c}0.0043 \\
(1.5883)\end{array}$ \\
\hline
\end{tabular}


B. Parameter estimates

\begin{tabular}{|c|c|c|c|c|}
\hline & Early/Small & Early/Large & Late/Small & Late/Large \\
\hline \multirow[t]{2}{*}{$a_{1}$} & 0.1550 & 0.1990 & 0.1794 & 0.1933 \\
\hline & $(0.0896)$ & $(0.0409)$ & $(0.2107)$ & $(0.2778)$ \\
\hline \multirow[t]{2}{*}{$\lambda$} & 5.3681 & 13.7766 & 13.5497 & 15.4017 \\
\hline & $(0.2320)$ & $(0.8079)$ & $(1.2331)$ & $(0.6924)$ \\
\hline \multirow[t]{2}{*}{$\delta$} & 0.0568 & 0.0421 & 0.0513 & 0.0715 \\
\hline & $(0.0030)$ & $(0.0016)$ & $(0.0026)$ & $(0.0007)$ \\
\hline \multirow[t]{2}{*}{$\rho_{\psi}$} & 0.4678 & 0.8062 & 0.5832 & 0.5435 \\
\hline & $(0.0707)$ & $(0.0602)$ & $(0.0384)$ & $(0.0404)$ \\
\hline \multirow[t]{2}{*}{$\sigma_{\psi}$} & 0.3592 & 0.1426 & 0.4402 & 0.3793 \\
\hline & $(0.0229)$ & $(0.0253)$ & $(0.0342)$ & $(0.0187)$ \\
\hline \multirow[t]{2}{*}{$\mu$} & -0.7955 & -1.2682 & -1.9547 & -1.5374 \\
\hline & $(0.0193)$ & $(0.0242)$ & $(0.0070)$ & $(0.0105)$ \\
\hline \multirow[t]{2}{*}{$\rho_{z}$} & 0.6486 & 0.3804 & 0.2086 & 0.2255 \\
\hline & $(0.0093)$ & $(0.0167)$ & $(0.0073)$ & $(0.0083)$ \\
\hline \multirow[t]{2}{*}{$\sigma_{z}$} & 0.3626 & 0.0500 & 0.4358 & 0.2839 \\
\hline & $(0.0123)$ & $(0.1103)$ & $(0.0280)$ & $(0.0203)$ \\
\hline \multirow[t]{2}{*}{$\nu_{i}$} & 24.5800 & 24.2204 & 21.1144 & 24.6259 \\
\hline & $(10.7767)$ & $(4.5446)$ & $(10.6082)$ & $(32.0085)$ \\
\hline \multirow[t]{2}{*}{$\nu_{r}$} & 5.9265 & 1.3097 & 10.4920 & 5.2683 \\
\hline & (1.4048) & $(2.8299)$ & (1.9924) & $(0.4364)$ \\
\hline \multirow[t]{2}{*}{$\rho_{z \psi}$} & 0.3538 & 0.4734 & 0.2842 & 0.0103 \\
\hline & $(0.0583)$ & $(1.0108)$ & $(0.1661)$ & $(0.0260)$ \\
\hline
\end{tabular}


Calculations are based on a sample of nonfinancial firms from the annual 2011 COMPUSTAT industrial files. The sample period is from 1987 to 2010. The sample is split into four groups: large and small firms in the first part of the sample (through 2003), and large and small firms in the second part of the sample. The estimation is done with SMM, which chooses structural model parameters by matching the moments from a simulated panel of firms to the corresponding moments from the data. Panel A reports the simulated and actual moments and the clustered t-statistics for the differences between the corresponding moments. Panel B reports the estimated structural parameters, with clustered standard errors in parentheses. $a_{1}$ is the linear equity issuance cost, $\lambda$ is the cost of adjusting the capital stock, and $\delta$ is the rate of capital depreciation. $\mu$ is the drift of the profitability process, $\rho_{z}$ is its serial correlation, and $\sigma_{z}$ is the standard deviation of the innovation to this process. $\rho_{\psi}$ and $\sigma_{\psi}$ are the serial correlation of the misvaluation process and the standard deviation of its innovation. $\rho_{z \psi}$ governs the serial correlation of the two processes. $\nu_{i}$ and $\nu_{r}$ are penalties on equity issuance and repurchases.

A. Moments

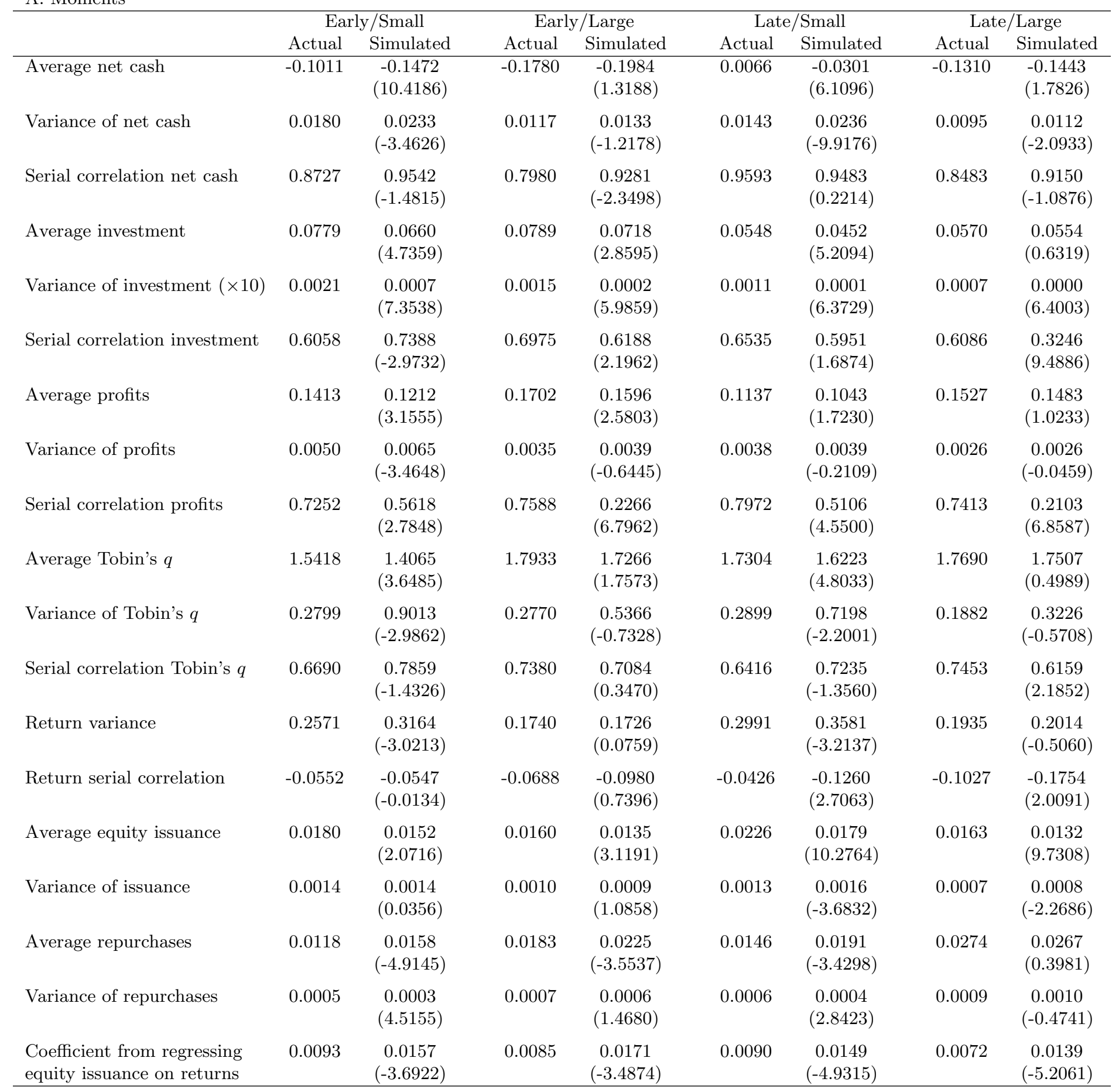


B. Parameter estimates

\begin{tabular}{|c|c|c|c|c|}
\hline & Early/Small & Early/Large & Late/Small & Late/Large \\
\hline \multirow[t]{2}{*}{$a_{1}$} & 0.0690 & 0.0061 & 0.0055 & 0.0011 \\
\hline & $(0.0453)$ & $(0.1181)$ & $(0.2746)$ & $(0.0267)$ \\
\hline \multirow[t]{2}{*}{$\lambda$} & 7.7674 & 13.3960 & 15.1163 & 16.2161 \\
\hline & $(0.6453)$ & $(0.6023)$ & $(0.9324)$ & $(0.9695)$ \\
\hline \multirow[t]{2}{*}{$\delta$} & 0.0559 & 0.0597 & 0.0594 & 0.0732 \\
\hline & $(0.0014)$ & $(0.0015)$ & $(0.0035)$ & $(0.0010)$ \\
\hline \multirow[t]{2}{*}{$\rho_{\psi}$} & 0.5235 & 0.6443 & 0.5756 & 0.5280 \\
\hline & $(0.1771)$ & $(0.0431)$ & $(0.0649)$ & $(0.0692)$ \\
\hline \multirow[t]{2}{*}{$\sigma_{\psi}$} & 0.3778 & 0.3225 & 0.4409 & 0.3475 \\
\hline & $(0.0398)$ & $(0.0107)$ & $(0.0189)$ & $(0.0114)$ \\
\hline \multirow[t]{2}{*}{$\mu$} & -0.9200 & -1.4663 & -1.1074 & -1.5479 \\
\hline & $(0.0201)$ & $(0.0227)$ & $(0.0294)$ & $(0.0205)$ \\
\hline \multirow[t]{2}{*}{$\rho_{z}$} & 0.5985 & 0.2301 & 0.5406 & 0.2114 \\
\hline & $(0.0100)$ & $(0.0106)$ & $(0.0114)$ & $(0.0073)$ \\
\hline \multirow[t]{2}{*}{$\sigma_{z}$} & 0.4797 & 0.3638 & 0.4607 & 0.3240 \\
\hline & $(0.0108)$ & $(0.0139)$ & $(0.0168)$ & $(0.0184)$ \\
\hline \multirow[t]{2}{*}{$\nu_{i}$} & 11.2939 & 10.7153 & 12.3839 & 11.6689 \\
\hline & $(1.8251)$ & $(2.9095)$ & $(4.9587)$ & $(1.4231)$ \\
\hline \multirow[t]{2}{*}{$\nu_{r}$} & 14.7551 & 8.6100 & 12.0823 & 6.4321 \\
\hline & $(0.6747)$ & $(1.4739)$ & $(1.2092)$ & $(0.5000)$ \\
\hline \multirow[t]{2}{*}{$\rho_{z \psi}$} & 0.4654 & 0.4548 & 0.3301 & 0.4305 \\
\hline & $(0.1855)$ & $(0.0636)$ & $(0.0734)$ & $(0.0385)$ \\
\hline
\end{tabular}

